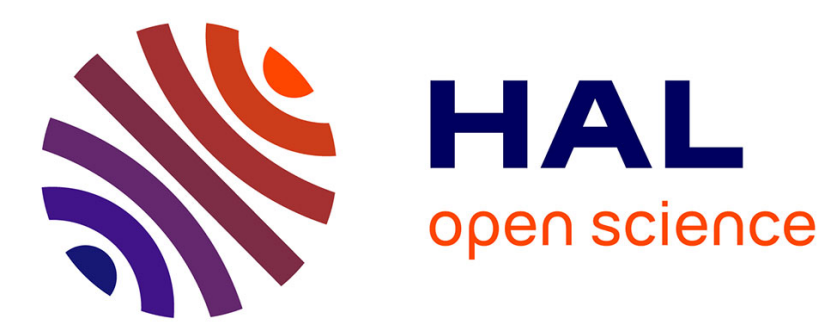

\title{
Crustal recycling, mantle dehydration, and the thermal evolution of Mars
}

\author{
A. Morschhauser, M. Grott, D. Breuer
}

\section{To cite this version:}

A. Morschhauser, M. Grott, D. Breuer. Crustal recycling, mantle dehydration, and the thermal evolution of Mars. Icarus, 2011, 212 (2), pp.541. 10.1016/j.icarus.2010.12.028 . hal-00734592

\section{HAL Id: hal-00734592 \\ https://hal.science/hal-00734592}

Submitted on 24 Sep 2012

HAL is a multi-disciplinary open access archive for the deposit and dissemination of scientific research documents, whether they are published or not. The documents may come from teaching and research institutions in France or abroad, or from public or private research centers.
L'archive ouverte pluridisciplinaire HAL, est destinée au dépôt et à la diffusion de documents scientifiques de niveau recherche, publiés ou non, émanant des établissements d'enseignement et de recherche français ou étrangers, des laboratoires publics ou privés. 


\section{Accepted Manuscript}

Crustal recycling, mantle dehydration, and the thermal evolution of Mars

A. Morschhauser, M. Grott, D. Breuer

PII:

S0019-1035(10)00496-3

DOI:

10.1016/j.icarus.2010.12.028

Reference:

YICAR 9679

To appear in:

Icarus

Received Date:

26 April 2010

Revised Date:

26 November 2010

Accepted Date:

25 December 2010

Please cite this article as: Morschhauser, A., Grott, M., Breuer, D., Crustal recycling, mantle dehydration, and the thermal evolution of Mars, Icarus (2010), doi: 10.1016/j.icarus.2010.12.028

This is a PDF file of an unedited manuscript that has been accepted for publication. As a service to our customers we are providing this early version of the manuscript. The manuscript will undergo copyediting, typesetting, and review of the resulting proof before it is published in its final form. Please note that during the production process errors may be discovered which could affect the content, and all legal disclaimers that apply to the journal pertain. 


\title{
Crustal recycling, mantle dehydration, and the thermal evolution of Mars
}

\author{
A. Morschhauser ${ }^{\mathrm{a}}$, M. Grott ${ }^{\mathrm{a}}$, D. Breuer ${ }^{\mathrm{a}}$ \\ ${ }^{a}$ Institute of Planetary Research, German Aerospace Center (DLR), Rutherfordstraße 2, 12489 Berlin, \\ Germany
}

\begin{abstract}
We have reinvestigated the coupled thermal and crustal evolution of Mars taking new laboratory data concerning the flow behavior of iron-rich olivine into account. The low mantle viscosities associated with the relatively higher iron content of the Martian mantle as well as the observed high concentrations of heat producing elements in a crust with a reduced thermal conductivity were found to promote phases of crustal recycling in many models. As crustal recycling is incompatible with an early separation of geochemical reservoirs, models were required to show no episodes of crustal recycling. Furthermore, admissible models were required to reproduce the Martian crust formation history, to allow for the formation of partial melt under present day mantle conditions and to reproduce the measured concentrations of potassium and thorium on the Martian surface. Taking dehydration stiffening of the mantle viscosity by the extraction of water from the mantle into account, we found that admissible models have low initial upper mantle temperatures around $1650 \mathrm{~K}$, preferably a primordial crustal thickness of $30 \mathrm{~km}$, and an initially wet mantle rheology. The crust formation process on Mars would then be driven by the extraction of a primordial crust after core formation, cooling the mantle to temperatures close to the peridotite solidus. According to this scenario, the second stage of global crust formation took place over a more extended period of time, waning at around 3500 Myr b.p., and was driven by heat produced by the decay of radioactive elements. Present-day volcanism would then be driven by mantle plumes originating at the core-mantle boundary under regions of locally thickened, thermally insulating crust. Water extraction from the mantle was found to be
\end{abstract}


relatively efficient and close to 40 percent of the total inventory was lost from the mantle in most models. Assuming an initial mantle water content of $100 \mathrm{ppm}$ and that $10 \%$ of the extracted water is supplied to the surface, this amount is equivalent to a $15 \mathrm{~m}$ thick global surface layer, suggesting that volcanic outgassing of $\mathrm{H}_{2} \mathrm{O}$ could have significantly influenced the early Martian climate and increased the planet's habitability. Keywords:

Mars, Mars, interior, Thermal histories, Volcanism, Geophysics

\section{Introduction}

The coupled crustal and thermal evolution of Mars is one of the outstanding problems in Martian geophysics and knowledge of the evolution of the crust can place important constraints on the thermal evolution of the planet. The thickness of the Martian crust has been constrained from various studies including analysis of localized admittance spectra (McGovern et al., 2002), analysis of geoid-to-topography ratios (Wieczorek and Zuber, 2004), viscous relaxation studies (Nimmo and Stevenson, 2001), and geochemical analysis of the

Martian meteorites (Norman, 1999, 2002). From these, a range of crustal thicknesses of $50 \pm 12 \mathrm{~km}$ was found to be consistent with all studies (Wieczorek and Zuber, 2004). A hard upper limit on the crustal thickness is placed by the absence of viscous relaxation of topography at the crustal dichotomy boundary (Nimmo and Stevenson, 2001) and crustal thickness is unlikely to exceed $100 \mathrm{~km}$.

The bulk of the Martian crust formed early in Martian history and Martian meteorite isotope data suggests an early mantle differentiation and the extraction of a primordial crust around 4.5 Gyr b.p. (Halliday et al., 2001; Nyquist et al., 2001). Using mass balance calculations, Norman (1999) constrained the thickness of this layer to $20-30 \mathrm{~km}$. A second stage of crustal formation later produced a 45-75 km thick secondary crust (Norman, 2002), and there is evidence that the crust of Mars is indeed stratified (Ruiz et al., 2006, 2009). It is generally assumed that the bulk of the crust was in place around the end of the Noachian epoch at 4 Gyr b.p. (Nimmo and Tanaka, 2005). The volumetrically largest late stage contribution to the Martian crust is marked by the emplacement of the Tharsis rise, 
which was essentially complete at the end of the Noachian period (Phillips et al., 2001) and changed little thereafter (Banerdt and Golombek, 2000).

Minor contributions to the Martian crust by basaltic volcanism are pervasive throughout Martian history and there is ample evidence for late crustal production even after 4 Gyr b.p. (Hartmann et al., 1999; Hartmann and Berman, 2000; Neukum et al., 2004; Grott, 2005; Hauber et al., 2009; Werner, 2009). However, late stage activity appears to be focused on the Tharsis and Elysium volcanic provinces. It has been speculated that this activity may be driven by hot mantle plumes (Kiefer and Li, 2009; Grott and Breuer, 2010). Such plumes have also been invoked to explain the formation of the Tharsis bulge (Harder and Christensen, 1996; Li and Kiefer, 2007; Kiefer and Li, 2009). Alternatively, volcanism may be driven by heat accumulation underneath regions of a thickened, thermally insulating crust (Schumacher and Breuer, 2007), or a combination of both processes (Grott and Breuer, 2009).

The coupled thermal and crustal evolution of Mars has been previously investigated in a number of studies using parameterized (Spohn, 1991; Hauck and Phillips, 2002; Breuer and Spohn, 2003, 2006; Schumacher and Breuer, 2006; Fraeman and Korenaga, 2010) as well as two dimensional (Li and Kiefer, 2007) and three dimensional (Keller and Tackley, 2009) convection models. In these models, the initial temperature distribution in the Martian interior as well as the viscosity structure of the Martian mantle were identified as the key parameters influencing mantle melting and the evolution of the Martian crust.

Coupled thermal and crustal evolution models have so far been constrained by the observed and inferred crust production rate (Hauck and Phillips, 2002; Breuer and Spohn, 2006) and the magnetic field history (Breuer and Spohn, 2006). With these constraints, two different classes of admissible models have been identified: On the one hand, a wet mantle rheology is compatible with the formation times as well as the overall volume of produced crust if low initial upper mantle temperatures are assumed (Hauck and Phillips, 2002; Breuer and Spohn, 2006). These models cool relatively efficiently and crustal production ceases around 3.5 Gyr b.p. with the vanishing of the global melt channel. On the other hand, a trade-off exists between initial temperatures and viscosity: Assuming higher 
initial temperatures, the existence of a primordial crust and a dry mantle rheology were also found to be compatible with the observations (Breuer and Spohn, 2006). This ambiguity has recently been investigated on the basis of elastic thickness estimates, which indicate that a dry mantle rheology is incompatible with the low elastic thicknesses suggested for the Noachian and early Hesperian periods (Grott and Breuer, 2008a, 2010).

New laboratory data on the creep behaviour of dry olivine indicates that the relatively higher iron content of the Martian mantle with respect to the Earth's reduces mantle viscosity on Mars by approximately one order of magnitude (Zhao et. al., 2009). Assuming that this also holds for wet olivine, reference viscosities previously identified with wet and dry rheologies need to be downward corrected by one order of magnitude, resulting in more vigorous mantle convection.

New data concerning the enrichment and concentration of radioactive elements in the Martian crust has been obtained from the gamma-ray spectrometer on board the Mars Odyssey spacecraft (Taylor et al., 2006). Radioactive elements were found to be distributed fairly homogeneously over the Martian surface and the crust was found to be more strongly enriched with heat producing elements than previously assumed. Given a crustal thickness of $45 \mathrm{~km}$, Taylor et al. (2006) estimate that about half the planets inventory of heat producing elements is situated in the crust, corresponding to an enrichment factor of about ten with respect to the undepleted mantle - more than twice as high as the enrichment usually found in terrestrial mid-ocean ridge basalts (BVSP, 1981). Furthermore, the compositional model by Dreibus and Wänke (1987) was found to best reproduce the ratio of K to Th abundances in the Martian interior and is now considered the standard compositional model for Mars. Radioactive elements in this model produce heat at a rate comparable to the chondritic heat production rate. Also, it is consistent with the Martian crust formation history (Hauck and Phillips, 2002) as well as the absence of viscous topographic relaxation at large impact basins (Grott and Breuer, 2008b).

The stronger enrichment of radioactive elements in the crust and its low thermal conductivity lead to a period of lithospheric thinning. Together with the lower reference viscosities, this promotes erosion of the stagnant lid from below and 
the stagnant lid thickness can thin below the crustal thickness in many models. Physically, this situation corresponds to a scenario in which crust is recycled back into the mantle, replenishing the mantle with enriched crustal material. Crustal erosion and recycling by mantle convection was alluded to in previous publications (Spohn, 1991; Breuer and Spohn, 2006; Keller and Tackley, 2009), but being on the margin of the admissible parameter space has never been studied in any detail. However, together with the assumption of a crust with reduced thermal conductivity, the new data indicates that crustal recycling should be the rule rather than the exception for a variety of models, justifying a reinvestigation of the crustal and thermal evolution of Mars. As argued below, crustal recycling is incompatible with an early separation of geochemical reservoirs (Jagoutz, 1991; Papike et al., 2009), and we will use the requirement that no crust must be recycled back into the mantle to constrain our models. Furthermore, models will be constrained by a comparison with the crust formation history as derived from observations, the measured concentration of potassium on the Martian surface as well as the requirement that formation of partial melt should be possible under present day mantle conditions. In the following, we will present a reinvestigation of the coupled crustal and thermal evolution of Mars, which will be studied using parameterized convection models. Extraction of partial melt from the mantle and the fractionation of heat producing elements into the crust are included in a self-consistent manner. Also, the dehydration of the mantle by volcanic outgassing will be investigated.

\section{Modelling}

\subsection{Thermal Evolution}

The thermal evolution of Mars is modeled starting from an initial temperature profile corresponding to the time after core formation. The evolution is then followed to the present by solving the energy balance equations for the core, the mantle and the lithosphere. Energy 
conservation in the mantle is given by

$$
\begin{aligned}
\rho_{m} c_{m} V_{l} \epsilon_{m}(1+S t) \frac{d T_{m}}{d t}= & -\left(q_{l}+\left(\rho_{c r} L+\rho_{c r} c_{c r}\left(T_{m}-T_{l}\right)\right) \frac{d D_{c r}}{d t}\right) A_{l}+ \\
& q_{c} A_{c}+Q_{m} V_{l}
\end{aligned}
$$

where $\rho_{m}$ and $c_{m}$ are the density and heat capacity of the mantle, $V_{l}$ is the volume of the convecting mantle given by $V_{l}=4 / 3 \pi\left(R_{l}^{3}-R_{c}^{3}\right), R_{c}$ the core radius, $R_{l}$ the radius of the base of the stagnant lid, $A_{l}$ and $A_{c}$ are the corresponding surface areas given by $A_{l}=4 \pi R_{l}^{2}$ and $A_{c}=4 \pi R_{c}^{2}$ and $D_{c r}$ is the crustal thickness. $T_{m}$ is the upper mantle temperature, $\epsilon_{m}$ is the ratio between the average and upper mantle temperature, and $S t$ is the Stefan number which accounts for the consumption and release of latent heat during melting and crystallization of mantle rock. $q_{l}$ is the heat flux from the convecting mantle into the base of the stagnant lid, $q_{c}$ is the heat flux from the core into the mantle and $t$ is time. The term proportional to the crustal growth rate $d D_{c r} / d t$ on the right hand side of Eq. 1 accounts for additional heat lost from the convecting mantle due to volcanic heat piping and $\rho_{c r}$ and $c_{c r}$ are the crustal density and heat capacity, respectively, $L$ is the latent heat of melting and $T_{l}$ is the temperature at the base of the stagnant lid. The mantle volumetric heating rate $Q_{m}$ depends on the amount of radioactive elements in the mantle. Here, the depletion of radioactive elements in the mantle and the associated enrichment of these elements in the crust will be calculated self-consistently using a fractional melting model which will be discussed in Sec. 2.3.

The Stefan number $S t$ is calculated from the averaged degree of melting $m_{a}$ in the melt zone and given by

$$
S t=\frac{L}{c_{m}} \frac{V_{a}}{V_{l}} \frac{d m_{a}}{d T_{m}}
$$

where $V_{a}$ is the volume of the melt zone. $V_{a}$ and $m_{a}$ are calculated from the assumed melting model (see below).

Energy conservation in the core is given by

$$
\rho_{c} c_{c} V_{c} \epsilon_{c} \frac{d T_{c}}{d t}=-q_{c} A_{c}
$$


where $\rho_{c}$ and $c_{c}$ are the density and heat capacity of the core, $V_{c}$ is the volume of the core given by $V_{c}=4 / 3 \pi R_{c}^{3}, T_{c}$ is the temperature at the core-mantle boundary, and $\epsilon_{c}$ is the ratio between the average and core-mantle boundary temperatures. Core-freezing (e.g., Stevenson et al. (1983)) is neglected in our model, as the core of Mars is generally assumed to be entirely molten due to its presumably high sulfur content (Stevenson, 2001).

The growth of the stagnant lid is determined by the energy balance at the lithospheric base (Schubert et al., 1979; Spohn and Schubert, 1982; Schubert and Spohn, 1990; Spohn, 1991), which is given by

$$
\rho_{m} c_{m}\left(T_{m}-T_{l}\right) \frac{d D_{l}}{d t}=-q_{l}+\left(\rho_{c r} L+\rho_{c r} c_{c r}\left(T_{m}-T_{l}\right)\right) \frac{d D_{c r}}{d t}-\left.k_{m} \frac{\partial T}{\partial r}\right|_{r=R_{l}}
$$

where $D_{l}$ is the stagnant lid thickness, $k_{m}$ is the mantle thermal conductivity and $\partial T /\left.\partial r\right|_{r=R_{l}}$ is the thermal gradient at the base of the stagnant lid which is determined from the temperature profile $T(r)$ in the stagnant lid. As heat is transported conductively in the stagnant lid, $T(r)$ is calculated by solving the heat conduction equation given by

$$
\frac{1}{r^{2}} \frac{\partial}{\partial r}\left(r^{2} k_{l} \frac{\partial T}{\partial r}\right)+Q_{l}=0
$$

Here, $r$ is the radial distance from the planetary centre and $k_{l}$ and $Q_{l}$ are the thermal conductivity and heat production rate in the stagnant lid, respectively. These have to be replaced by their respective values $k_{m}, k_{c r}$ and $Q_{m}, Q_{c r}$ in the lithospheric mantle and crust. As boundary conditions, the surface temperature $T_{s}$ and the temperature $T_{l}$ at the base of the stagnant lid (cf. Eq. 8) will be used.

It follows from Eq. 4 that the growth of the stagnant lid is determined by the balance between heat provided to the base of the lid from the convecting mantle and the ability of the lithospheric rocks to conduct this heat. Note that heat conduction in the lid is strongly influenced by the crustal thermal conductivity $k_{c r}$ and crustal heat production rate $Q_{c r}$. A low crustal thermal conductivity and a high concentration of heat producing elements in the crust result in a thermal insulation of the lid and reduced stagnant lid thicknesses. By including a heat-piping term proportional to 
the crustal growth rate in the energy balance at the lithospheric base we assume that the bulk of the extracted melt originates from a region close to or inside the upper thermal boundary layer. This is equivalent to the heat-piping case considered by Spohn (1991). The other end-member case, in which volcanic heat transfer bypasses the stagnant lid and heat is provided to the lithospheric base purely conductively will not be considered in detail here. However, we will briefly discuss the influence of neglecting volcanic heat-piping in Eq. 4 when discussing our results in Sec. 4.

The evolution of Mars is driven by the efficiency of mantle energy transport and Mars is in the stagnant lid regime of mantle convection (Solomatov and Moresi, 1997; Reese et al., 1998). We use scaling laws for stagnant lid convection by Grasset and Parmentier (1998) to parameterize heat flow as a function of Rayleigh number, which is defined as

$$
R a=\frac{\alpha \rho_{m} g \Delta T\left(R_{l}-R_{c}\right)^{3}}{\kappa \eta}
$$

where $\Delta T=T_{m}-T_{l}+T_{c}-T_{b}$ and $T_{b}$ is the temperature at the base of the mantle, $\kappa$ is the mantle thermal diffusivity, $\alpha$ is the thermal expansivity, $g$ the surface gravitational acceleration and $\eta$ the mantle viscosity. The mantle viscosity is temperature-dependent and given by

$$
\eta=\eta_{0} \exp \left(\frac{A}{R} \frac{\left(T_{r e f}-T_{m}\right)}{T_{r e f} T_{m}}\right)
$$

where $\eta_{0}$ is the reference viscosity at the respective reference pressure $p_{\text {ref }}$ and temperature $T_{\text {ref }}, R$ is the gas constant, and $A$ is the activation energy for diffusion creep.

To calculate the convection driving temperature difference $\Delta T$, the temperature $T_{l}$ at the base of the stagnant lid and the temperature $T_{b}$ at the base of the mantle need to be known. $T_{l}$ has been determined using two-dimensional Cartesian mantle convection models (Davaille and Jaupart, 1993; Grasset and Parmentier, 1998; Choblet and Sotin, 2000) and was found to be the temperature at which the viscosity has grown by one order of magnitude with respect to the convecting mantle. It is thus a function of mantle temperature and the rate of change of viscosity with temperature and is given by

$$
T_{l}=T_{m}-\Theta \frac{R T_{m}^{2}}{A}
$$


where $\Theta=2.21$ is usually assumed (Grasset and Parmentier, 1998). To account for spherical symmetry, $\Theta=2.9$ is used here, which was derived from a comparison of the model presented here to the two-dimensional mantle convection models by Reese et al. (2005). This change results in a small increase of the surface heat flux as compared to the previously used value of $\Theta=2.21$, which is of little influence when studying the general thermal evolution, but has noticeable effects on the melt productivity considered here. The temperature $T_{b}$ at the base of the mantle is determined by the adiabatic temperature increase in the mantle and

$$
T_{b}=T_{m}+\frac{\alpha g T_{m}}{c_{m}} \Delta R
$$

where $\Delta R=R_{l}-R_{c}-\delta_{u}-\delta_{c}$ and $\delta_{u}$ and $\delta_{c}$ are the thicknesses of the upper and lower thermal boundary layer, respectively.

The heat flow out of the mantle $q_{l}$ and the core $q_{c}$ are calculated from

$$
q_{l}=k_{m} \frac{T_{m}-T_{l}}{\delta_{u}}
$$

and

$$
q_{c}=k_{m} \frac{T_{c}-T_{b}}{\delta_{c}}
$$

and the thickness of the upper thermal boundary layer is derived from boundary layer theory (Turcotte and Schubert, 2002). It is given by

$$
\delta_{u}=\left(R_{l}-R_{c}\right)\left(\frac{R a_{\text {crit }}}{R a}\right)^{\beta}
$$

where $R a_{\text {crit }}$ is the critical Rayleigh number of the mantle and $\beta=1 / 3$. The thickness of the lower thermal boundary layer is given by

$$
\delta_{c}=\left(\frac{\kappa f_{c} \eta_{c} R a_{i, c r i t}}{\alpha \rho_{m} g_{c}\left(T_{c}-T_{b}\right)}\right)^{\frac{1}{3}}
$$

where $g_{c}$ is the gravitational acceleration at the core-mantle boundary, $f_{c}$ is a factor accounting for the pressure dependence of the viscosity, and $\eta_{c}$ is the viscosity at the average temperature $\eta\left(\left(T_{c}+T_{b}\right) / 2\right)$ in the lower thermal boundary layer (Richter, 1978). For the lower 
thermal boundary layer, Deschamps and Sotin (2001) found that a local critical Rayleigh number $R a_{i, c r i t}$ depending on the internal Rayleigh number $R a_{i}$ should be used instead of $R a_{\text {crit }}$ of Eq. 12. The internal Rayleigh number is defined as

$$
R a_{i}=\frac{\alpha \rho_{m} g \Delta T_{i}\left(R_{p}-R_{c}\right)^{3}}{\kappa \eta}
$$

where $\Delta T_{i}=T_{m}-T_{s}+T_{c}-T_{b}$ and the internal critical Rayleigh number was found to be

$$
R a_{i, c r i t}=0.28 R a_{i}^{0.21}
$$

\subsection{Crustal Evolution}

Partial melting in the mantle, melt extraction, and crustal formation have a huge influence on the thermal evolution of Mars and we will present our model for the crustal evolution in this section. We follow an approach similar to that of Breuer and Spohn $(2003,2006)$ and Schumacher and Breuer (2006), but explicitly take the increase of the mantle solidus upon depletion of crustal components into account. Thus, we need to modify their equation for crustal growth accordingly.

The presence of partial melt in the mantle depends on the solidus of mantle rocks and the temperature profile in the mantle. Partial melt will be present whenever the ambient temperature exceeds the pressure dependent solidus of mantle rocks. Here, we assume that the first melting mantle component is peridotite. Therefore, we use the parameterization for the peridotite solidus and liquidus by Takahashi (1990) to determine the degree of partial melting. The peridotite solidus is given by

$$
T_{\text {sol }, \text { Peridotite }}=1409+134.2 P-6.581 P^{2}+0.1054 P^{3}
$$

where the pressure $P$ is in units of GPa. Using the same parameterization, the liquidus is given by

$$
T_{l i q}=2035+57.46 P-3.487 P^{2}+0.0769 P^{3}
$$

After extraction of crustal components, the solidus of the mantle residue will increase and we will assume a linear increase of $T_{\text {sol }}$ with proceeding depletion of the mantle. 
A total maximum solidus change of $\Delta T_{\text {sol }}=150 \mathrm{~K}$ has been determined between undepleted and depleted peridotite (Maaløe, 2004), i.e. harzburgite. Hence, we will use

$$
T_{\text {sol }}=T_{\text {sol,Peridotite }}+\frac{D_{c r}}{D_{\text {ref }}} \Delta T_{\text {sol }}
$$

as a parameterization for the mantle solidus. Here, $D_{r e f}$ is a reference crustal thickness defined such that the solidus increase equals $\Delta T_{\text {sol }}$ after the extraction of $20 \%$ of the total silicate volume, i.e.,

$$
D_{\text {ref }}=\frac{0.2}{3} \frac{R_{p}^{3}-R_{c}^{3}}{R_{p}^{2}}
$$

The volumetrically averaged degree of melting can then be calculated from

$$
m_{a}=\frac{1}{V_{a}} \int_{V_{a}} \frac{T(r)-T_{\text {sol }}(r)}{T_{l i q}(r)-T_{\text {sol }}(r)} d V
$$

where $V_{a}$ is the volume of the meltzone, i.e., that portion of the mantle where partial melt is present and $T(r)$ is the calculated mantle temperature profile. Due to the higher compressibility of basaltic melt with respect to mantle rock, melt looses its buoyancy at pressures around 6 GPa (Suzuki et al., 1998; Ohtani et al., 1998). Consequently, we only consider meltzones shallower than the corresponding depth in the following.

Note that Eq. 20 implies a linear relationship between the degree of partial melt and the normalized temperature difference between solidus and liquidus, yet in reality this relationship is nonlinear primarily due to the exhaustion of clinopyroxene (McKenzie and Bickle, 1988; Katz et al., 2003). Different parameterizations for the dependence of the degree of partial melt on temperature and pressure have been derived based on thermodynamic considerations and experimental data (McKenzie and Bickle, 1988; Iwamori et al., 1995; Ghiorso et al., 2002; Katz et al., 2003) and a comparison of these parameterizations shows that systematic differences exist at very low and very high degrees of melting (Katz et al., 2003). For this reason, Katz et al. (2003) suggest that a linear relationship should be used to reconcile the different models, which is the approach adopted here. 
Finally, assuming that crust will be distributed uniformly on the planetary surface, the rate of crustal growth can be calculated from

$$
\frac{d D_{c r}}{d t}=u m_{a} \frac{V_{a}}{4 \pi R_{p}^{3}}
$$

where the mantle convection velocity $u$ is given by

$$
u=u_{0}\left(\frac{R a}{R a_{\text {crit }}}\right)^{2 \beta}
$$

and $u_{0}$ is the mantle convective velocity scale. Thus we assume that the timescale for melt extraction is governed by the rate at which undepleted material can be supplied to the partial melt zone. Note that, depending on plume size, melt ascent in plumes and dikes can be much faster than this timescale for individual melt parcels. However, the local solidus increase will cut-off the melt supply until undepleted material is transported to the meltzone, a process occurring at the convective velocity scale.

After a phase of rapid growth due to volcanic heat extraction, many of our models show a rapidly thinning stagnant lid due to the inefficient heat transport from the lithospheric base. Lithospheric thinning is promoted by the presence of a highly enriched, low thermal conductivity crust and in many cases the stagnant lid thickness $D_{l}$ becomes smaller than the crustal thickness $D_{c r}$. In this case, we will assume that crust will be recycled into the mantle by the vigorous convective motion and that

$$
D_{c r}=\min \left(D_{c}, D_{l}-\epsilon\right)
$$

where the offset $\epsilon=100 \mathrm{~m}$ is introduced for reasons of numerical stability. Recycling of the crust into the mantle is promoted by the basalt to eclogite phase transformation, which on Mars occurs at depths between 50 and $150 \mathrm{~km}$ (Babeyko and Zharkov, 2000), depending on temperature. Eclogite has a density similar to that of mantle material, thus leading to a loss of buoyancy of the crustal component.

\subsection{Fractionation of heat producing elements}

The amount of radiogenic heating in the mantle and in the crust depends on the bulk concentration of radioactive nuclides and their distribution between crust and mantle. The 
radiogenic heating rate $H_{i}^{0}(t)$ is decreasing with time due to radioactive decay and is given by

$$
H_{i}^{0}(t)=H_{i} \exp \left(-\lambda_{i} t\right)
$$

where the index i extends over all relevant radioactive species, i.e. thorium, uranium and potassium, and $\lambda_{i}$ and $H_{i}$ are the species half life and heat generation rate, respectively (Turcotte and Schubert, 2002). The volumetric heat generation rate therefore depends on time and the concentration of the respective radioactive species in the host rock which is different for the mantle and the crust.

The extraction of radioactive elements from the mantle is calculated selfconsistently assuming accumulated fractional melting. The concentration $X_{i}^{l i q}$ of heat producing elements in the liquid phase of the partial melt can be calculated from the bulk mantle concentrations $X_{i}^{m}$ and partition coefficients $D_{i}$ for each of the heat producing elements $i$, respectively. It is given by

$$
X_{i}^{l i q}=\frac{X_{i}^{m}}{F}\left[1-(1-F)^{1 / D_{i}}\right]
$$

where

$$
\hat{F}=\frac{T-T_{s o l}}{T_{l i q}-T_{s o l}}
$$

is the depth dependent melt fraction. The partition coefficients $D_{i}$ are similar for all relevant heat producing elements (Beattie, 1993). It is $D_{i} \sim 0.01$ for the partitioning of heat producing elements from clinopyroxene into the melt, $D_{i} \sim 0.004$ for the garnet-melt system and vanishingly small in all other systems (Hart and Dunn, 1996; Hauri et al., 1994). For the composition model of Wänke and Dreibus (1994) we obtain $D_{i} \sim 0.002$. As $D_{i} \ll 1$, the partial melt and thus the crust are strongly enriched in heat producing elements with respect to the mantle.

To determine the total amount of heat producing elements extracted from the mantle, we average their depth-dependent concentration $X_{i}^{l i q}$ in the melt 
over the entire melt zone

$$
\bar{X}_{i}^{l i q}=\frac{1}{m_{a} V_{a}} \int_{V_{a}} X_{i}^{l i q} F d V
$$

The total mass $M_{i}^{s c r}$ for each species of heat producing elements in the secondary crust which has been extracted from the mantle is calculated from

$$
\frac{d M_{i}^{s c r}}{d t}=\bar{X}_{i}^{l i q} \frac{d M_{c r}}{d t}
$$

where $M_{c r}=4 / 3 \pi\left(R_{p}^{3}-\left(R_{p}-D_{c r}\right)^{3}\right) \rho_{c r}$ is the mass of the crust and $M_{i}^{s c r}(t=0)=0$.

The enrichment of heat producing elements in the primordial crust, which formed from a magma ocean, probably differs from that of the secondary crust. This is taken into account by treating the extraction of heat producing elements during the first stage of crustal production separately. The amount of radioactive elements in the primordial crust after accretion is parameterized by

$$
M_{i}^{p c r}=\Lambda X_{i}^{0} M_{c r}^{0}
$$

where $X_{i}^{0}$ is the bulk concentration of heat producing elements in the primitive mantle given by the compositional model of Wänke and Dreibus (1994), $M_{c r}^{0}=$ $4 / 3 \pi\left(R_{p}^{3}-\left(R_{p}-D_{c r}^{0}\right)^{3}\right) \rho_{c r}$ is the total mass of the primordial crust and $\Lambda$ is the crustal enrichment factor of heat producing elements in relation to the primitive mantle.

The mantle concentration of heat producing elements at any time $t$ can then be determined from mass balance considerations and is given by

$$
X_{i}^{m}(t)=\frac{X_{i}^{0} M-M_{i}^{c r}(t)}{M_{m}(t)}
$$

where $M_{m}$ is the mass of the mantle given by $M_{m}=4 / 3 \pi\left(\left(R_{p}-D_{c}\right)^{3}-R_{c}^{3}\right) \rho_{m}, M=$ $4 / 3 \pi\left(R_{p}^{3}-R_{c}^{3}\right)$ is the total mass of the primordial silicate mantle and $M_{i}^{c r}(t)$ is the total mass of each of the heat producing species in the crust given by

$$
M_{i}^{c r}(t)= \begin{cases}M_{i}^{s c r}(t), & \text { if } D_{c r}^{0}=0 \\ M_{i}^{s c r}(t)+M_{i}^{p c r}, & \text { if } D_{c r}^{0}>0\end{cases}
$$


where $D_{c r}^{0}$ is the thickness of the primordial crust.

The mantle volumetric heating rate $Q_{m}(t)$ can then be calculated from

$$
Q_{m}(t)=\rho_{m} \sum_{i} X_{i}^{m}(t) H_{i}^{0}(t)
$$

To calculate the cumulative heating rate in the crust, some assumptions regarding the distribution of heat producing elements within the crust need to be made. Although it has been argued that the crust could be stratified (Norman, 1999, 2002; Ruiz et al., 2006, 2009), impact gardening and intrusive volcanism would act to largely remove any initial compositional heterogeneities. Therefore, we assume that heat producing elements are distributed homogeneously within the crust (Taylor et al., 2006). In this case, the crustal volumetric heating rate is given by

$$
Q_{c r}(t)=\rho_{c r} \sum_{i} \frac{M_{i}^{c r}(t)}{M_{c r}(t)} H_{i}^{0}(t)
$$

\subsection{Mantle Dehydration}

Water behaves similar to other moderately incompatible elements and will preferably move to the liquid phase upon partial melting. Thus it will be extracted from the mantle during the crust formation process. By considering water to behave as a regular trace element, its accumulated fractional partitioning between solid and silicate melt can be determined using a bulk distribution coefficient (Katz et al., 2003). The concentration of water remaining in the mantle then follows from mass balance considerations and the successive dehydration of the mantle during crust formation will be described in the following.

Given the bulk concentration of water in the mantle rock $X_{H_{2} 0}^{m}$ and the partitioning coefficient for water $D_{\mathrm{H}_{2} \mathrm{O}}$ between solid and silicate melt, the concentration of water in the melt can be determined using a fractional melting model similar to that used for heat producing elements and

$$
X_{\mathrm{H}_{2} \mathrm{O}}^{l i q}=\frac{X_{\mathrm{H}_{2} \mathrm{O}}^{m}}{F}\left[1-(1-F)^{1 / D_{\mathrm{H}_{2} \mathrm{O}}}\right]
$$

where $D_{H_{2} \mathrm{O}}=0.01$ (Katz et al., 2003; Aubaud et al., 2004). $X_{\mathrm{H}_{2} \mathrm{O}}^{\text {liq }}$ is the cumulative concentration of water in the silicate melt, provided that the concentration does not exceed 
the pressure dependent saturation concentration. The maximum amount of water soluble in the melt is given by

$$
X_{H_{2} O}^{s a t}=\chi_{1} P^{\xi}+\chi_{2} P
$$

where $\chi_{1}, \chi_{2}$ and $\xi$ are experimentally determined constants and $\chi_{1}=12 \mathrm{wt} \% \mathrm{GPa}^{-\xi}$, $\chi_{2}=1 \mathrm{wt} \% \mathrm{GPa}^{-1}$ and $\xi=0.6$ (Katz et al., 2003). Combining Eqs. 34 and 35, the amount of water in the liquid phase is given by the minimum of the cumulative and saturation concentrations and $X_{\mathrm{H}_{2} \mathrm{O}}^{l i q}:=\min \left(X_{\mathrm{H}_{2} \mathrm{O}}^{l i q}, X_{\mathrm{H}_{2} \mathrm{O}}^{\text {sat }}\right)$.

The concentration of water in the melt therefore depends on the local melt fraction as well as on the local saturation concentration. To determine the total amount of water extracted from the mantle, we average the concentration of water in the melt over the entire meltzone

$$
\bar{X}_{H_{2} O}^{l i q}=\frac{1}{m_{a} V_{a}} \int_{V_{a}} X_{H_{2} O}^{l i q} F d V
$$

and calculate the total mass $M_{H_{2} O}^{s c r}$ of water in the secondary crust from

$$
\frac{d M_{\mathrm{H}_{2} \mathrm{O}}^{s c r}}{d t}=\bar{X}_{\mathrm{H}_{2} \mathrm{O}}^{\mathrm{liq}} \frac{d M_{c r}}{d t}
$$

The extraction of water from the mantle therefore depends on the decreasing concentration $X_{H_{2} O}^{m}$ of water in the mantle as well as the crustal production rate $d M_{c r} / d t$. Water extraction and degassing during the formation of a primordial crust from an early magma ocean is not considered here. Instead, the initial bulk water concentration $X_{\mathrm{H}_{2} \mathrm{O}}^{0}$ should correspond to a value after formation of the primordial crust. Therefore, $M_{\mathrm{H}_{2} \mathrm{O}}^{c r}=M_{\mathrm{H}_{2} \mathrm{O}}^{s c r}$ and the mantle water content at time $t$ is given by

$$
X_{H_{2} O}^{m}(t)=\frac{X_{\mathrm{H}_{2} \mathrm{O}}^{0} M-M_{\mathrm{H}_{2} \mathrm{O}}^{c r}(t)}{M_{m}}
$$

Note that the amount of water transported to the crust is the same as the mass of water extracted from the mantle as the crust entirely consists of extracted mantle material. Part of this water will be outgassed into the atmosphere through extrusive volcanism. 


\section{Parameters}

Parameters most sensitively influencing the coupled thermal and crustal evolution of Mars have been identified in previous studies (Hauck and Phillips, 2002; Breuer and Spohn, 2006). In these studies, mantle viscosity, the initial upper mantle temperature, as well as the bulk content of radiogenic elements were found to have the largest influence on model results. We will discuss our choice of these parameters as well as the influence of a primordial crust of variable thickness in the following. Other parameters used in the modeling are summarized in Table 1.

The viscosity of the Martian mantle is governed by the flow behavior of olivine, which strongly depends on mineral water content (Mei and Kohlstedt, 2000a,b). The viscosity of anhydrous and water saturated olivine differs by two orders of magnitude (Karato and Wu, 1993) and already small amounts of water can be rheologically significant (Mei and Kohlstedt, 2000a,b). The amount of water present in the Martian mantle is poorly constrained and estimates range from relatively low water contents of 36 ppm (Wänke and Dreibus, 1994) to extremely large water contents in excess of 1000 ppm (Johnson et al., 1991). Geochemical analysis of the SNC meteorites suggest that the SNC parent magmas contained considerable amounts of water (McSween et al., 2001; Médard and Grove, 2006), but given their relatively shallow crystallization depths a crustal origin of this water cannot be ruled out. On the other hand, even the lowest estimated water concentrations of $36 \mathrm{ppm}$ would be about 20 and $60 \%$ saturated in olivine at 300 and $100 \mathrm{~km}$ depth, respectively (Hirth and Kohlstedt, 1996), such that a wet mantle rheology appears to be best compatible with all data. We will use a normalized water concentration when calculating mantle dehydration with $X_{H_{2} \mathrm{O}}^{m}$ ranging between zero and one and a normalized initial mantle water content of $X_{\mathrm{H}_{2} \mathrm{O}}^{0}=1$, which corresponds to a rheologically wet mantle.

Recent experiments on the influence of iron content on the creep behaviour of olivine indicate that a high iron content can significantly decrease mantle viscosity. In particular, the relatively higher iron content of the Martian mantle with respect to Earth's reduces mantle viscosity on Mars by approximately one order of magnitude (Zhao et. al., 2009). 
Using flow law parameters appropriate for diffusion creep in olivine (Karato and Wu, 1993), reference viscosities of $10^{19}$ and $10^{21} \mathrm{~Pa}$ s have been obtained at a reference temperature of $1600 \mathrm{~K}$ for wet and dry Earth-like material, respectively (Breuer and Spohn, 2006). Reducing these numbers by one order of magnitude, we will vary $\eta_{0}$ between $10^{18}$ and $10^{21} \mathrm{~Pa} \mathrm{~s}$ to cover the whole range of plausible viscosities, spanning the range from iron-rich wet olivine to Earth-like dry material.

Reasonable initial upper mantle temperatures $T_{m}^{0}$ range from $1600 \mathrm{~K}$ to $2300 \mathrm{~K}$, where the lower limit is close to the solidus of peridotite and the upper limit is close to its liquidus (Takahashi, 1990). Initial temperatures below the solidus are unlikely if one allows for silicate and mantle melting during core formation. Also, it is highly unlikely that the Martian mantle remained above the liquidus for any significant period of time (Spohn and Schubert, 1990). This range of initial temperatures can be further constrained from the crust formation history as high initial temperatures close to the liquidus result in extremely large crustal thicknesses, which are incompatible with the observations (Hauck and Phillips, 2002; Breuer and Spohn, 2006). Therefore, we will here vary initial upper mantle temperatures between 1600 and $1900 \mathrm{~K}$.

Models for the bulk abundance of heat producing elements in the Martian interior fall into two categories. The first class of models produce heat at a rate comparable to the chondritic heat production rate (Dreibus and Wänke, 1987; Treiman et al., 1986; McDonough and Sun, 1995) and the second class of models produce about twice as much (Lodders and Fegley, 1997). Hauck and Phillips (2002) found that the model by Lodders and Fegley (1997) is incompatible with the Martian crust formation history, as the high heat production rates in this model result in extensive mantle melting and extremely large crustal thicknesses. Furthermore, Grott and Breuer (2008b) found that such large heat production rates would result in the viscous relaxation of topography at the large impact basins. Consequently, we will not consider the model by Lodders and Fegley (1997) in the following. New data concerning the concentration of radioactive elements in the Martian crust have been obtained from the gamma-ray spectrometer on board the Mars Odyssey spacecraft (Taylor et al., 2006). They found that the measured ratio of the $\mathrm{K}$ and $\mathrm{Th}$ abundances in the Martian crust 
is best compatible with the compositional model by Dreibus and Wänke (1987). Therefore, we will use their model in the following.

Different parameterizations for the solidus of peridotite have been derived from melting experiments (McKenzie and Bickle, 1988; Takahashi, 1990; Zhang and Herzberg, 1994; Herzberg et al., 2000; Hirschmann, 2000; Katz et al., 2003). Melting models are summarized in Fig. 1 where the peridotite solidus is given as a function of pressure for different models. Apart from early work by McKenzie and Bickle (1988), which suffered from the lack of available data at high pressures, all models are in good agreement. Note that the parameterizations derived by Herzberg et al. (2000) and Zhang and Herzberg (1994) are valid only for pressures above 2.5 and $5 \mathrm{GPa}$, respectively, such that models in general agree to within $50 \mathrm{~K}$. In terms of the coupled thermal and crustal evolution of Mars, choosing one parameterization over another is roughly equivalent to a change of initial upper mantle temperature by $50 \mathrm{~K}$. Here we choose the model by Takahashi (1990), which is valid between 0 and $10 \mathrm{GPa}$ and covers the full range of pressures considered here.

Martian meteorite isotope data suggests an early mantle differentiation and the extraction of a primordial crust around 4.5 Gyr (Halliday et al., 2001; Nyquist et al., 2001). The thickness of this crustal layer has been constrained to 20-30 km (Norman, 1999). In addition, heat flows derived from elastic thickness data indicate that the Martian crust is indeed stratified (Ruiz et al., 2006, 2009). Therefore, we will consider two end-member cases in the following. One with an initial primordial crustal thickness $D_{c r}^{0}$ of $30 \mathrm{~km}$ and another without a primordial crust.

If existing, the primordial crust will probably be enriched in radioactive elements while emerging from an early Martian magma ocean, but the enrichment of radioactive elements in a putative magma ocean on Mars is not well constrained. However, the enrichment should be bracketed by that usually found in komatite and basalt, i.e., ranging from equal partitioning to an enrichment factor of roughly five. The fraction $f_{p}$ of radioactive elements which have been extracted from the primordial mantle can then be calculated assuming a thickness and an enrichment factor for the primordial crust. Using an enrichment 
factor of five together with the assumption of a $30 \mathrm{~km}$ thick primordial crust, we obtain that $f_{p}=12 \%$ of the radioactive elements in the primitive mantle are located in the crust. Variations of this value will be briefly discussed in Sec. 4.5.

\section{Results}

\subsection{Crustal evolution and recycling}

We have calculated the coupled crustal and thermal evolution of Mars varying the initial upper mantle temperature $T_{m}^{0}$ between 1600 and $1900 \mathrm{~K}$ and the reference viscosity $\eta_{0}$ between $10^{18}$ and $10^{21} \mathrm{~Pa}$ s. The results of a typical model run assuming an initial upper

mantle temperature of $1650 \mathrm{~K}$, a reference viscosity of $\eta_{0}=10^{18} \mathrm{~Pa}$, and a primordial crust of $30 \mathrm{~km}$ thickness are shown in Fig. 2. In Fig. 2a, the stagnant lid thickness $D_{l}$ and crustal thickness $D_{c r}$ are shown as a function of time. Within the first $10 \mathrm{Myr}$, the crustal thickness $D_{c r}$ rapidly grows to $45 \mathrm{~km}$ and the magmatic heat-piping connected to the melt extraction causes the stagnant lid to rapidly grow to a thickness of $85 \mathrm{~km}$. The relatively thick low conductivity crust, which is highly enriched in radioactive elements, then acts as an insulating layer and heat transport from the base of the stagnant lid by heat conduction becomes increasingly inefficient. This results in a phase of thinning of the lid until the stagnant lid thickness equals the crustal thickness at around $80 \mathrm{Myr}$. At this point, crustal recycling sets in and the growth of the crust is limited by the evolution of the stagnant lid thickness. At around 520 Myr the global melt channel vanishes and crustal production is halted, inhibiting a further increase of the thermal blanketing effect caused by the crust. At this point in time, the stagnant lid starts to grow again and the remaining evolution is governed by planetary cooling. Therefore, crustal recycling acts to limit the attainable crustal thickness in this model.

Fig. $2 \mathrm{~b}$ shows the upper mantle temperature $T_{m}$, the temperature at the core-mantle boundary $T_{c}$ and the temperature at the base of the crust $T_{c r}$ as a function of time. The superheated core rapidly cools until the temperature difference across the core-mantle boundary reaches $\sim 55 \mathrm{~K}$. Due to the low mantle viscosity and effective heat transport, 
the entire evolution is characterized by planetary cooling and mantle temperatures drop by $\sim 260 \mathrm{~K}$ until the present day. Temperatures at the base of the crust rapidly increase as the crust gets thicker and the crustal base is pushed to ever increasing depths. At the onset of crustal recycling crustal temperatures stabilize at around $1400 \mathrm{~K}$ before planetary cooling starts to reduce $T_{c r}$ to $510 \mathrm{~K}$ today.

The heat flow out of the mantle into the stagnant lid $q_{l}$, the heat flow out of the core $q_{c}$, and the surface heat flux $q_{s}$ are shown as a function of time in Fig. 2c. At 600 Myr, heat flow from the core rapidly drops below $20 \mathrm{~mW} \mathrm{~m}^{-2}$, the upper limit on the critical heat flow necessary for the generation of a thermally driven core dynamo (Nimmo and Stevenson, 2000). Due to the removal of heat producing elements to the crust, surface heat flow increases in the early evolution and drops to about $20 \mathrm{~mW} \mathrm{~m}^{-2}$ today, while mantle heat flow drops from 75 to $10 \mathrm{~mW} \mathrm{~m}^{-2}$.

The normalized concentration of water in the Martian mantle $X_{\mathrm{H}_{2} \mathrm{O}}^{m}$ is shown as a function of time in Fig. 2d and continually drops from the normalized initial value of $X_{\mathrm{H}_{2} \mathrm{O}}^{m}=1$ to $\mathbf{0 . 1 9}$ as long as melt is extracted from the mantle. Note that melt and water extraction continue during the phases of crustal erosion and $X_{H 2 O}^{m}$ only stabilizes with the vanishing of the global melt layer. Therefore, the Martian mantle looses $82 \%$ of its total water inventory due to outgassing in this model. This value is much higher than predicted by Hauck and Phillips (2002), but similar to the $\mathbf{8 0} \%$ suggested by Fraeman and Korenaga (2010).

Crustal production rates as a function of time are shown in Fig. 2e. In general, crustal production declines rapidly as a function of time, though it shows a small peak at the onset of crustal erosion. The position and extent of the meltzone is indicated by shades in Fig. 2f where the base of the stagnant lid as well as the crustal thickness are indicated by a dashed and solid line, respectively. Due to the rapid growth of the stagnant lid in the early phases of the evolution, the meltzone is pushed to a depth of $\sim 120 \mathrm{~km}$, before shrinking of the lid allows the meltzone to migrate to a depth of $\sim 80 \mathrm{~km}$. At around $520 \mathrm{Myr}$, mantle temperatures have dropped such that the global melt layer finally vanishes.

Average melt fractions encountered in this model amount to $5 \%$ on average. However, 
melt fractions locally reach about $10 \%$, consistent with melt fractions derived from trace element analysis of the shergottites, which range from 2 to $10 \%$ (Norman, 1999; Borg and Draper, 2003).

Results of varying initial upper mantle temperature and reference viscosity are shown in Figs. 3a and 3b, respectively, where the crustal thickness $D_{c r}$ is shown as a function of time for different models. For initial upper mantle temperatures in excess of $1600 \mathrm{~K}$, models with a reference viscosity of $\eta_{0}=10^{19} \mathrm{~Pa}$ s (Fig. 3a) show crustal recycling in the early evolution, which limits the final crustal thickness to $\sim 80 \mathrm{~km}$. For $T_{m}^{0}=1600 \mathrm{~K}$, crustal growth in the early evolution is much slower and the present day crustal thickness is only $32 \mathrm{~km}$. Results of varying the reference viscosity while keeping the initial upper mantle temperature constant at $1700 \mathrm{~K}$ are shown in Fig. 3b. There, the low viscosity models show crustal recycling. Stabilization of the crust only sets in for $\eta_{0} \geq 10^{20} \mathrm{~Pa}$ s. These models show a prolonged phase of crustal production due to the inefficient cooling of the planet.

The models for which crustal recycling is observed are identified in Fig. 4, where the fraction of the eroded crustal volume with respect to the present day crustal volume is given as a function of initial upper mantle temperature for different reference viscosities. Models without a primordial crust are shown in Fig. 4a whereas those with a primordial crust of $30 \mathrm{~km}$ thickness are shown in Fig. 4b. Crustal erosion is found to be widespread and only models on the abscissa show no signs of crustal recycling. Crustal recycling is promoted by high initial upper mantle temperatures $T_{m}^{0}$ and low reference viscosities $\eta_{0}$. Between these two quantities, a clear trade-off can be observed: Higher $T_{m}^{0}$ can be sustained without any recycling of the crust, as long as mantle viscosity is sufficiently high.

Crustal recycling appears to be incompatible with the SNC geochemical characteristics as these suggest the presence of three to four silicate reservoirs that all formed in the very early evolution of the planet and did not remix since then (e.g., Jagoutz, 1991; Papike et al., 2009). Therefore, we rule out models showing crustal recycling. Inspecting Fig. 4a, we conclude that only models with initial upper mantle temperatures below or equal to 
$1600,1650,1700$ and $1800 \mathrm{~K}$ for reference viscosities of $10^{18}, 10^{19}, 10^{20}$, and $10^{21} \mathrm{~Pa} \mathrm{~s}$ are compatible with the SNC observations. Fig. 4b shows the results for models with a primordial crustal thickness of $30 \mathrm{~km}$. The general trend for these is similar, yet initial upper mantle temperatures need to be lower by $\sim 50 \mathrm{~K}$ to prevent crustal recycling. Note that for $D_{c r}^{0}=30 \mathrm{~km}$, no model is able to fit the observations for a reference viscosity of $10^{18}$ Pa s.

The presented results have been obtained assuming that heat-piping is an efficient process to cool the base of the stagnant lid, such that the lid rapidly grows during the phases of early crust production. If the heat-piping term is removed from Eq. 4, crustal recycling will be promoted and more models will show crustal recycling in Fig. 4. In these models, the present day crustal thickness will be smaller than presented in Figs. 3a and 3b, but the overall volume of produced crust will be similar. Therefore, outgassing of $\mathrm{H}_{2} \mathrm{O}$ will be an efficient process in these models as well.

\subsection{Crust formation history}

To be compatible with the geological evidence, models need to reproduce the crust formation history visible in the surface record as well as the average volume of produced crust. Here we will use the fact that the bulk of the crust has been produced within the first 500 Myr (Phillips et al., 2001; Nimmo and Tanaka, 2005) to constrain the timing of crust formation. To quantify this, we will assume that $75 \%$ of the crust needs to be emplaced before 500 Myr, similar to the nominal model by Hauck and Phillips (2002). For the overall crustal thickness, the observation that no viscous relaxation of topography is visible at the dichotomy boundary will be used as a constrain, which requires $D_{c r}<100 \mathrm{~km}$ (Nimmo and Stevenson, 2001). This can be viewed as a hard upper limit on $D_{c r}$, but note that most studies indicate a lower crust thickness of around $50 \mathrm{~km}$ (Wieczorek and Zuber, 2004). A lower limit of $33 \mathrm{~km}$ is provided by the minimum average crustal thickness found in geoid-to-topography studies (Wieczorek and Zuber, 2004).

Fig. 5a and $\mathbf{b}$ show the fraction of crust produced within the first 500 Myr after differentiation as a function of initial upper mantle temperature $T_{m}^{0}$ for different reference 
viscosities $\eta_{0}$ without and with a primordial crust, respectively. Values above $100 \%$ indicate early produced crust which was later removed by crustal erosion. Low viscosity models tend to produce crust very early in the evolution, as the efficient mantle convection results in a relatively shallow melt zone. For $\eta_{0}=10^{18} \mathrm{~Pa} \mathrm{~s}$, all models produce essentially all crust within the first 500 Myr. Models without a primordial crust are shown in Fig. 5a. For a reference viscosity of $\eta_{0}=10^{19} \mathrm{~Pa}$ s, only models with $T_{m}^{0} \geq 1650 \mathrm{~K}$ are compatible with the constraint that $75 \%$ of the crust needs to be produced early. Higher initial upper mantle temperatures of $1800 \mathrm{~K}$ and $1900 \mathrm{~K}$ are required for $\eta_{0}=10^{20}$ and $10^{21} \mathrm{~Pa} \mathrm{~s}$, respectively. If we assume that a primordial crust is present at the beginning of the evolution (Norman, 1999; Halliday et al., 2001; Nyquist et al., 2001), models using a dry mantle rheology will comply somewhat better with the requirement of early crust formation. Results assuming $D_{c r}^{0}=30 \mathrm{~km}$ are shown in Fig. $5 \mathrm{~b}$. In this case, minimum initial upper mantle temperatures need to exceed only $1750 \mathrm{~K}$ and $1850 \mathrm{~K}$ for $\eta_{0}=10^{20}$ and $10^{21} \mathrm{~Pa}$ s, respectively.

Present day crustal thicknesses for models assuming no initial crustal thickness and assuming $D_{c r}^{0}=30 \mathrm{~km}$ are shown in Fig. 5c and 5d, respectively. The admissible range of crustal thicknesses is indicated by the horizontal dashed lines. Results differ little between $D_{c r}^{0}=0$ and $30 \mathrm{~km}$ and most models comply with the upper limit of $D_{c r}<100$ $\mathrm{km}$. This is due to the fact that present day crustal thickness is limited by crustal recycling in most models, as indicated by the horizontal trend of the respective lines. Only if $\eta_{0} \geq 10^{20}$ Pa s and $T_{m}^{0} \geq 1750 \mathrm{~K}, D_{c r}$ will exceed $100 \mathrm{~km}$.

Taking together the constraints posed by the crust formation history and the fact that models must not show any sign of crustal recycling, we find that only few models satisfy both constraints: For $\eta_{0}=10^{18} \mathrm{~Pa} \mathrm{~s}$, a primordial crust can be ruled out and $T_{m}^{0}$ needs to be $1600 \mathrm{~K}$. For $\eta_{0}=10^{19} \mathrm{~Pa} \mathrm{~s}, T_{m}^{0}$ needs to be $1650 \mathrm{~K}$ and $1600 \mathrm{~K}$ for models with and without a primordial crust, respectively. A dry mantle with a reference viscosity of $\eta_{0} \geq 10^{20} \mathrm{~Pa}$ s can be ruled out on the grounds that the low initial upper mantle temperatures required to inhibit crustal recycling and to produce a crust of $D_{c r}<100 \mathrm{~km}$ are incompatible with the requirement that 
the bulk of the crust was formed early in Martian history.

The concentration and distribution of potassium and thorium on the Martian surface has been measured using the gamma-ray spectrometer on board Mars Global Surveyor and it was found that the average concentration of these elements on the Martian surface is 0.62 and 3300 ppm, respectively (Taylor et al., 2006). As concentrations vary on the Martian surface, we will use the spatial standard deviation of the experimental data as a limit for our models, which is approximately $20 \%$ of the respective concentrations (Taylor, G.J., priv. comm.). Furthermore, as potassium and thorium have similar partition coefficients, it is sufficient to consider only one of these elements. The measured values of potassium are compared to the calculated values in Fig. 6 and the admissible range is indicated by dashed lines. Without a primordial crust (Fig. 6a), initial mantle temperatures $T_{m}^{0}$ should be $\leq 1750 \mathrm{~K}$ for dry mantle rheologies and $\geq 1700 \mathrm{~K}$ for wet mantle rheologies. However, if a primordial crust is included, a wider range of models is in accordance with the observations. This is mainly due to the constant enrichment of radioactive elements in the primordial crust. In this case, only high mantle viscosities together with high initial mantle temperatures are incompatible with the observations (Fig. 6b).

In summary, only the model with a reference viscosity of $\eta_{0}=10^{19} \mathrm{~Pa}$, a low initial mantle temperature of $1650 \mathrm{~K}$ and a primordial crust of $D_{c r}^{0}=30 \mathrm{~km}$ is compatible with all observations. Models without a primordial crust can be ruled out, as the predicted concentrations of heat producing elements in the crust are too high for the required low initial mantle temperatures and viscosities.

\subsection{Recent volcanism}

A final constraint on our models is posed by the observation that volcanism was pervasive throughout Martian history and has probably been ongoing into the very recent past (Hartmann et al., 1999; Hartmann and Berman, 2000; Neukum et al., 2004; Werner, 2009). Therefore, melting should be possible under present day mantle conditions and this will be 
used to constrain our models in the following.

As shown by the models presented in the previous sections (e.g. Fig. 3), global volcanism on Mars ceased between 500 and 2000 Myr after core formation and we cannot expect a global melt channel to exist today. However, this does not preclude the formation of local meltzones and there are indeed two alternative hypotheses for the persistence of volcanism on Mars today: First, recent production of partial melt in the Martian mantle could be caused by decompression melting in the heads of uprising mantle plumes (O'Neill et al., 2007; Li and Kiefer, 2007) and second, melting could be caused by heat accumulation underneath regions of a thickened, thermally insulating crust (Schumacher and Breuer, 2007).

In order to determine whether present day partial melting is feasible in our models, we calculate the temperature rising mantle plumes would have and compare it to the solidus of peridotite. In this way, the excess temperature needed to induce melting and the distance mantle plumes would have to penetrate into the stagnant to allow for decompression melting can be calculated. In our parameterized models, mantle plumes would originate at the core-mantle boundary. Thus, the initial plume temperature is given by the core temperature $T_{c}$. Plumes then cool adiabatically as they rise to the surface and plume temperature is given by

$$
T_{\text {plume }}(z)=T_{c}-\frac{\alpha g T_{c} z}{c_{m}}
$$

where $z$ is the distance from the core-mantle boundary.

Given the plume and solidus temperatures $T_{\text {plume }}$ and $T_{\text {sol }}$, we compute the minimum temperature difference $\Delta T_{\text {min }}$ between $T_{\text {plume }}$ and $T_{\text {sol }}$

$$
\Delta T_{\text {min }}=\left.\min \left(T_{\text {sol }}(z)-T_{\text {plume }}(z)\right)\right|_{z \leq\left(R_{p}-R_{c}-D_{l}\right)}
$$

to determine if partial melt is generated in the convecting mantle below the stagnant lid. Furthermore, the distance $D_{\text {melt }}$ mantle plumes would have to penetrate into the stagnant lid from below to initiate decompression melting is calculated. This distance corresponds to the depth at which $T_{\text {plume }}$ equals $T_{\text {sol }}$ and can be decreased under regions of thickened and thermally insulating crust, where plume temperatures have 
been increased by $100 \mathrm{~K}$ (Schumacher and Breuer, 2007). As the feasibility of recent volcanism turned out to be independent of the existence of a primordial crust, the following models are presented only for models including a primordial crust of $30 \mathrm{~km}$ thickness.

Results of calculating $\Delta T_{\min }$ for the range of models considered in this study are presented in Fig. 7a. Low viscosity models cool very efficiently, resulting in low present day mantle temperatures requiring substantial local heating of more than $350 \mathrm{~K}$ to initiate partial melting. Given that the temperature excess provided by the thermal blanketing effect of a low conductivity crust is of the order of only $100 \mathrm{~K}$ (Schumacher and Breuer, 2007), this is clearly insufficient to initiate melting. Only models with $\eta_{0}=10^{21} \mathrm{~Pa}$ s would barely allow for the production of melt today. However, these models produce crust too late in the evolution and have been ruled out in the previous section.

The distance $D_{\text {melt }}^{100}$ mantle plumes would have to penetrate into the stagnant lid under a locally thickened crust is given in percent of the stagnant lid thickness as a function of $T_{m}^{0}$ and $\eta_{0}$ in Fig. 7b. Higher viscosity models have less efficient mantle energy transport and more heat can be stored inside the planet over the course of the evolution. The relatively larger present day stagnant lid thickness for high viscosity models adds to the fact that plumes need not penetrate far into the stagnant lid to initiate partial melting for $\eta_{0}=10^{20}$ and $\eta_{0}=10^{21} \mathrm{~Pa}$. However, these models have been ruled out in previous sections as they are incompatible with a predominantly early production of crust or the absence of crustal recycling. Models compatible with these constraints have reference viscosities below $\eta_{0}=10^{20} \mathrm{~Pa} \mathrm{~s}$ and inspecting Fig. $7 \mathrm{~b}$ we find that plumes would need to penetrate $\sim 90$ and $\sim 75 \%$ into the stagnant lid for $\eta_{0}=10^{18}$ and $10^{19} \mathrm{~Pa} \mathrm{~s}$, respectively. This is larger than the penetration depths discovered in mantle convection models, which indicate that long-lived mantle-plumes can penetrate into the stagnant lid by more than $50 \%$ of the stagnant lid thickness (Buske, 2006; Kiefer and Li, 2009).

In summary, the model best compatible with the absence of crustal recycling, the concentration of heat producing elements in the crust and the crust formation history has a low initial upper mantle temperature of $T_{m}^{0}=1650 \mathrm{~K}$, a low 
viscosity of $\eta_{0}=10^{19} \mathrm{~Pa} \mathrm{~s}$ and a primordial crust of $D_{c r}^{0}=30 \mathrm{~km}$ thickness. However, considering that plumes would need to penetrate $\sim 80 \%$ into the stagnant lid to initiate decompression melting even under a locally thickened, thermally insulating crust, this set of parameters is only marginally acceptable.

One way to facilitate present day melt production would be to increase mantle viscosity late in the evolution, while keeping viscosity low during the early evolutionary stages. In this way, heat would be released from the interior at a reduced rate, while early crust formation would not be affected. Given that the models considered so far loose a significant amount of water from the mantle due to volcanic outgassing, dehydration stiffening of the mantle would be one way to increase viscosity in the course of the evolution. This possibility will be investigated in the next section.

\subsection{Dehydration stiffening}

The viscosity of water-saturated and anhydrous olivine varies by more than two orders of magnitude (Karato and $\mathrm{Wu}, 1993$ ) and we will treat the viscosity of the Martian mantle as a function of mantle water content in the following. We will assume that viscosity increases linearly between these two end-member cases. To this end, we will parameterize the reference viscosity $\eta_{0}$ using the normalized mantle water concentration $X_{H_{2} O}^{m}$. In the case considered here, $X_{\mathrm{H}_{2} \mathrm{O}}^{m}$ should be equal to unity for a rheologically wet mantle. Dehydration stiffening is then accounted for by changing the reference viscosity $\eta_{0}$ in Eq. 7 according to

$$
\eta_{0}\left(X_{H_{2} O}^{m}\right)=\eta_{w e t}\left(1+\Delta \eta\left(1-X_{H_{2} O}^{m}\right)\right)
$$

where $\eta_{w e t}=10^{18} \mathrm{~Pa}$ s is the viscosity of wet olivine and $\Delta \eta=100$ a factor accounting for the viscosity difference between wet and dry olivine, respectively. Therefore, viscosities range from values of $10^{18} \mathrm{~Pa}$ s representative for wet, iron-rich olivine to $10^{20} \mathrm{~Pa}$ s, representative for dry, iron-rich olivine.

Results of the calculations including dehydration stiffening are presented in Table 2, where models are identified by their initial upper mantle temperature $T_{m}^{0}$ and primordial 
crustal thickness $D_{c r}^{0}$. For models including a primordial crust, the enrichment factor $\Lambda$ is also given. Only those models which do not show crustal recycling are considered and for each model the present day crustal thickness $D_{c r}^{4500}$, the fraction $f_{c r}^{500}$ of crust produced before $500 \mathrm{Myr}$, the minimum temperature difference $\Delta T_{\min }$ between the mantle solidus and plumes, the distance mantle plumes would have to penetrate into the stagnant lid to initiate decompression melting expressed as a fraction of the stagnant lid thickness $f=1-D_{\text {melt }} / D_{l}$ and the analogue fraction $f_{100}$ assuming a mantle locally heated by 100 $\mathrm{K}$ as well as the percentage of mantle water lost $f_{\mathrm{H}_{2} \mathrm{O}}$ and the ratio of calculated to measured concentrations of potassium in the crust $K_{c a} / K_{m e}$ are given.

For most models, the present day crustal thickness is in the admissible range and the bulk of this crust is produced at an early evolutionary stage. However, the total volume of crust produced in models with low initial mantle temperatures and without a primordial crust is too small as the minimum average crustal thickness may not be lower than $33 \mathrm{~km}$ (Wieczorek and Zuber, 2004). Also, the presence of a primordial crust is favoured by the calculated potassium concentrations which are generally too high for models without a primordial crust and only the model with $T_{m}^{0}=1700 \mathrm{~K}$ is barely feasible. Assuming a primordial crust with $D_{c r}^{0}=30$ $\mathrm{km}$, the best fitting model has an initial mantle temperature of $T_{m}^{0}=1650 \mathrm{~K}$. In this model, melting by excess heating in regions of a thickened crust is possible if $\Delta T_{\min } \sim 300 \mathrm{~K}$ and therefore unlikely to cause mantle melting on its own. On the other hand, decompression melting gets efficient if thermal insulation by a thick crust is taken into account. In this case, $f_{100}$ indicates that the distance mantle plumes need to penetrate into the stagnant lid in order to induce melting is reduced to $\sim 56 \%$. Therefore, dehydration stiffening of the mantle viscosity faciliates present day volcanism as expected. The best fitting model compatible with all observations has the same initial mantle temperature of $1650 \mathrm{~K}$ and a primordial crust of 30 $\mathrm{km}$ as the best fitting model without dehydration stiffening. However, recent volcanism is easier to explain if dehydration stiffening is taken into account. Other models presented in Table 2 consider the effects of varying the enrichment 
of radioactive elements in the primordial crust, which will be discussed in Sec. 4.5.

Fig. 8 is similar to Fig. 2 and shows the results for the preferred model including dehydration stiffening in some more detail. For this model, an initially wet mantle rheology with $\eta_{0}=10^{18} \mathrm{~Pa} \mathrm{~s}$, an initial mantle temperature of $T_{m}^{0}=1650 \mathrm{~K}$ and a primordial crust with a thickness of $D_{c r}^{0}=30 \mathrm{~km}$ have been assumed, and this model may be directly compared to the results presented in Fig. 2 for a model without dehydration stiffening and $T_{m}^{0}=1650 \mathrm{~K}, \eta_{0}=10^{18} \mathrm{~Pa} \mathrm{~s}$, and $D_{c r}^{0}=30 \mathrm{~km}$. Results are similar, but the model including dehydration stiffening does not show any crustal recycling because mantle viscosity rapidly increases by a factor of $\mathbf{4 0}$ in the first Gyr as in this interval the mantle water content is reduced by $40 \%$. The absence of crustal recycling and the associated larger stagnant lid thickness also result in lower temperatures at the crustal base, where maximum $T_{c r}$ is close to $1050 \mathrm{~K}$ for only a limited period of time. Upper mantle temperatures increase during the first $650 \mathrm{Myr}$ of the evolution due to the less efficient heat transport, resulting in sustained crustal production over that time-period. The global melt layer vanishes at $970 \mathrm{Myr}$, about 450 Myr later than in the model without dehydration stiffening. This is already indicating the reduced rate at which heat is lost from the mantle.

\subsection{Model sensitivity to additional processes}

The growth of the stagnant lid as presented in Eq. 4 is determined by the energy balance at the lithospheric base. When more heat is transported through the lithospheric mantle towards the surface than is provided to the base of the lid by the mantle boundary layer, the stagnant lid will cool and therefore grow. Heat producing elements in the crust and lithospheric mantle can insulate the base of the stagnant lid and therefore hamper effective heat removal, resulting in a relatively lower stagnant lid thickness. As heat producing elements are highly incompatible and therefore effectively transported from the mantle into the crust, the residual rocks in the global mantle melt zone are depleted in radioactive elements. In this work, we assumed that such a layer will efficiently 
be remixed with pristine mantle material through vigorous convective motion. However, it cannot be excluded that a depleted layer in the lithospheric mantle could persist. To investigate the influence of such a depleted mantle layer, we have calculated an extreme case for which we assumed that all heat producing elements have been removed from the lithospheric mantle. Results indicate a decrease of the present crustal thickness by $5 \%$ in comparison to the model with a homogeneously mixed mantle. This small difference between models assuming either a homogeneously mixed or a layered mantle with respect to heat sources has also been suggested by Fraeman and Korenaga (2010).

In our derivation of the crustal growth rate in Eq. 21, we assumed that the melt zone is global whenever the calculated average mantle temperature exceeds the solidus temperature. However, this may not be true in regions of convective downwelling where temperatures are generally lower. In the case of symmetrical upwelling and downwelling, the crustal production rate in Eq. 21 would be reduced by a factor of two. In this case, we found that the reduced crustal growth is outbalanced by a less efficient extraction of heat producing elements and reduced volcanic heat-piping from the mantle. This leads to a generally hotter planet, capable of producing thicker melt zones over an extended period of time. Therefore, crustal thicknesses increase by $\sim 9 \%$ for a half as efficient crustal production rate in our model. This result is in agreement with Fraeman and Korenaga (2010) and Hauck and Phillips (2002), who introduced a variable factor in the crustal production rate to account for this effect and found that results vary only marginally by varying this factor.

The enrichment of radioactive elements in the secondary crust is calculated self-consistently in our model, but this approach cannot be applied to the primordial crust which probably formed during overturn of an early magma ocean (Elkins-Tanton et al., 2005). In this study, we have assumed a primordial crustal thickness of $D_{c r}^{0}=30 \mathrm{~km}$ and an enrichment factor of $\Lambda=5$ for radioactive elements in the primordial crust, which implies that $12 \%$ of all radioactive elements 
have been extracted into the primordial crust during its formation process. This enrichment is similar to the enrichment factors typically encountered in mid-ocean ridge basalts on Earth (BVSP, 1981). However, the exact differentiation process in a Martian magma ocean is unknown and significantly higher or lower enrichments are possible. Hence, we investigated models including dehydration stiffening for different enrichment factors. For these models, resulting concentrations of potassium in the crust are then compared to the measured concentrations (Taylor et al., 2006).

Results of these calculations are shown in Fig. 9, where the ratios of calculated to measured concentrations of potassium in the Martian crust are shown for different enrichment factors $L a m b d a$ and initial mantle temperatures $T_{m}^{0}$. For enrichment factors greater than five, concentrations of potassium in the Martian crust become too large for low $T_{m}^{0}$. On the other hand, lower enrichment factors lead to concentrations of potassium better compatible with the observations for cold mantle temperatures and all models result in too low crustal potassium concentrations for $T_{m}^{0} \geq 1800 \mathbf{K}$.

To test the robustness of our results, all models with and without dehydration stiffening have been recalculated assuming no enrichment of radioactive elements in the primordial crust $(\Lambda=1)$ to test the robustness of our results. We find that all conclusions presented in this study remain unchanged as model results change only little. As an example, the results for an initial mantle temperature of $T_{m}^{0}=1650 \mathbf{K}$ and a crustal enrichment factor of $\Lambda=1$ are shown in Table 2. Compared to the model using $\Lambda=5$, the largest difference is a slightly increased crustal thickness of $D_{c}=65 \mathrm{~km}$, indicating that models are relatively insensitive to low values of $\Lambda$. Note, however, that low enrichment factors are rather unrealistic, as the crustal component should be significantly enriched in incompatible elements when forming from completely molten material.

Crustal erosion vanishes for enrichment factors of $\Lambda=10,20$ even when choosing higher initial mantle temperatures up to $T_{m}^{0}=1700 \mathrm{~K}$, but the concentration 
of potassium in the Martian crust will be too high for initial mantle temperatures below $T_{m}^{0}=1700 \mathrm{~K}$. The results for models with high enrichment factors and $T_{m}^{0}=1700$ are compared to the models with an enrichment factor of $\Lambda=5$ in Table 2. These models are compatible with all constraints and crustal thicknesses tend to be higher than for the admissible model with $\Lambda=5$. This is caused by the higher initial mantle temperatures necessary to explain the measured concentration of potassium in the Martian crust. However, mantle plumes will have to penetrate 10 and $15 \%$ deeper into the stagnant lid to enable recent volcanism on Mars, as a more depleted mantle leads to lower mantle temperatures in the late stage of the evolution. Therefore, models assuming $\Lambda=10,20$ are also admissible, provided that initial mantle temperatures are slightly increased.

\section{Discussion and Conclusions}

We have reinvestigated the coupled thermal and crustal evolution of Mars taking new laboratory data concerning the flow behavior of iron-rich olivine into account. The lower mantle viscosities (Zhao et. al., 2009) in combination with an insulating crust were found to promote phases of extensive shrinking of the stagnant lid thickness early in the evolution, with stagnant lid thicknesses rapidly approaching the crustal thickness in many models. We interpret the expansion of the actively convecting region into the crust in terms of a recycling of crustal material back into the mantle. This process is facilitated by the basalt to eclogite phase transformation, which on Mars occurs at depths between 50 and 150 km (Babeyko and Zharkov, 2000), depending on temperature. Eclogite has a density similar to that of mantle material and crustal material will loose buoyancy due to this phase-change.

Geochemical analysis of the SNC meteorites such as the ${ }^{182} \mathrm{~W}-{ }^{142} \mathrm{Nd}$ isotope and ReOs systematics (e.g., Lee and Halliday (1997); Brandon et al. (2000); Foley et al. (2005)) imply the presence of three to four isotopically distinct silicate reservoirs on Mars. Two of these reservoirs are depleted in incompatible lithophile elements relative to chondrites, and the third is enriched. The two depleted reservoirs are most likely located in the Martian mantle, while the enriched reservoir could be either in the mantle or the crust. These 
source reservoirs of the SNC meteorites appear to have remained separate for almost the entire history of Mars (4-4.5 Ga). Crustal recycling would have destroyed any early mantle reservoirs (Jagoutz, 1991) and we require that admissible models do not show episodes of crustal recycling.

Further evidence against models exhibiting phases of crustal recycling is provided by the absence of viscous topographic relaxation at the dichotomy boundary and the large impact basins. Crustal flow will relax isostatically supported topography if the base of the crust is too hot (Nimmo and Stevenson, 2001; Parmentier and Zuber, 2007) and basal temperatures in excess of 1200-1250 K were found to result in efficient lower crustal flow (Grott and Breuer, 2008b; Mohit and Phillips, 2007). Models exhibiting crustal erosion have crustal basal temperatures in excess of $1400 \mathrm{~K}$ for extensive periods of time, such that for these models viscous relaxation of topography would be expected. On the other hand, models showing no crustal recycling have much lower crustal temperatures and peak temperatures reach only $1050 \mathrm{~K}$, making crustal flow unlikely.

Further model constraints are provided by the inferred crust formation history and we required that $75 \%$ of the crust was emplaced within the first 500 Myr after core formation (Phillips et al., 2001; Nimmo and Tanaka, 2005) in admissible models. Also, the present day crustal thickness must not exceed $100 \mathrm{~km}$ (Nimmo and Stevenson, 2001) to be compatible with the absence of viscous relaxation at the dichotomy boundary. The content and distribution of heat producing elements in the Martian crust has been measured using gamma-ray spectroscopy (Taylor et al., 2006) and admissible models must be able to reproduce the observed crustal concentrations of these elements. Finally, we required that admissible models must allow for the formation of partial melt under present day mantle conditions as volcanism is a recent process on Mars (Hartmann et al., 1999; Hartmann and Berman, 2000; Neukum et al., 2004; Werner, 2009).

Taken together, these constraints limit the range of admissible models significantly: Models are required to posses a primordial crust to be compatible with the crust formation history and the measured concentration of radioactive elements in the crust. Only low initial upper mantle temperatures around $1650 \mathrm{~K}$ are compatible with the absence of crustal 
recycling. Furthermore, admissible reference viscosities are around $10^{19} \mathrm{~Pa}$ s, and even then models are only marginally compatible with the existence of present day volcanism.

Model compatibility with the above constraints is improved if the increase of mantle viscosity upon loss of water from the mantle is taken into account. These models cool less efficiently, increasing present day mantle temperatures and facilitating the production of partial melt, while crust production during the early phases of the evolution is only marginally affected. In this way, these models better satisfy the constraints posed by the crust formation history and the existence of present day volcanism. Initial upper mantle temperatures in these models need to be between 1650 and $1700 \mathrm{~K}$, and the best fitting model with $T_{m}^{0}=1650 \mathrm{~K}$ and $D_{c r}^{0}=30 \mathrm{~km}$ has a present day crustal thickness of $59 \mathrm{~km}, 93 \%$ of which was emplaced before 500 Myr. These results suggest that Martian interior temperatures after core formation were reduced to close to the peridotite solidus upon extraction of the primordial crust. A second stage of crust formation then took place over a more extended period of time, waning at around $1000 \mathrm{Myr}$, and was driven by heat produced by the decay of radioactive elements. In these models, present-day volcanism is driven by longlived mantle plumes under regions of a locally thickened, thermally insulating crust.

Dehydration stiffening of the mantle rheology results in thick thermal boundary layers, which grow as the viscosity of the mantle is increased over time. Therefore, models accounting for mantle water loss show larger stagnant lid thicknesses. Hence, estimates of the elastic thicknesses obtained in these models are increased. Using the best fitting model determined here (cf. Fig. 8), we calculate a present day stagnant lid thickness of $330 \mathrm{~km}$. This value is about $80 \mathrm{~km}$ larger than values typically obtained when dehydration stiffening is disregarded. Using the model by Grott and Breuer (2010), this increase of the stagnant lid thickness results in an elastic thickness of $250 \mathrm{~km}$ at the north pole today, reducing the discrepancy between derived (Phillips et al., 2008) and modeled values from $100 \mathrm{~km}$ to only $50 \mathrm{~km}$. Therefore, taking dehydration stiffening of the mantle into account, the spatial heterogeneity of the Martian mantle heat 
flow does not need to be as strong as previously estimated. However, this would still argue for active mantle plumes on Mars today.

The results presented here are similar to those obtained by Hauck and Phillips (2002), who also found that cold initial temperatures and low mantle viscosities best fit the inferred crust formation history, although their preferred models have slightly higher initial upper mantle temperatures between 1700 and $1800 \mathrm{~K}$. However, part of this discrepancy is explained by the use of different parameterizations for the peridotite solidus, with Hauck and Phillips (2002) using the parameterization by Zhang and Herzberg (1994), which results in solidus temperatures which are about $70 \mathrm{~K}$ higher than the values adopted here (Takahashi, 1990). While Breuer and Spohn (2006) found that models using high initial upper mantle temperatures and high mantle viscosities are also admissible if the existence of a primordial crust is assumed, we have ruled out these models on the grounds that they show episodes of crustal recycling.

The dehydration of the Martian mantle upon partial melting and melt extraction has been studied by Hauck and Phillips (2002) and they found it difficult to extract more than a few percent of water from the mantle, while $40-50 \%$ of water are easily extracted from the mantle in our models. This efficient water extraction is consistent with the models by Fraeman and Korenaga (2010), which indicate a mantle water loss of $\sim 80$ $\%$ for crustal thicknesses larger than $50 \mathrm{~km}$. However, it is considerably larger than the amount of extracted water calculated by Hauck and Phillips (2002), which is only $5 \%$. This very low value is similar to the volume fraction of crust produced in their models when compared to the volume of the primitive mantle and would be consistent with a distribution coefficient of $D=1$ for water. Also, the fraction of heat producing elements extracted from the mantle is larger than the fraction of extracted water in their models. This indicates that the distribution coefficient used for water is larger than that used for the heat producing elements, which Hauck and Phillips (2002) chose to be $D=0.1$ in their nominal model. Therefore, the low amount of water extracted in their models might be due to the use of a comparatively large distribution coefficient 


\section{for water.}

Assuming an initial mantle water content of 100 ppm, the extracted amount of water in our preferred model is equivalent to a $150 \mathrm{~m}$ thick global surface layer, and the concentration of water in the melt ranges from 800 to 2100 ppm. Even if only $10 \%$ of magma is erupted onto the Martian surface (Lillis et al., 2009), volcanic outgassing of $\mathrm{H}_{2} \mathrm{O}$ could still have significantly contributed to the surface water inventory, strongly influencing the early climate and increasing the habitability of early Mars.

\section{Acknowledgments}

We wish to thank two anonymous reviewers for their comments, which helped to improve this manuscript. This research has been supported by the Helmholtz Association through the research alliance "Planetary Evolution and Life". 


\section{References}

Aubaud, C., Hauri, E.H., Hirschmann, M.M., 2004. Hydrogen partition coefficients between nominally anhydrous minerals and basaltic melts, Geophys. Res. Lett., 31, 20, CiteID L20611, doi:10.1029/2004GL021341

Banerdt, W.B., Golombek, M.P., 2000. Tectonics of the Tharsis region of Mars: Insights from MGS topography and gravity, Proc. Lunar Planet. Sci. Conf. 31 $1^{\text {st }}$, abstract 2038.

Babeyko, A.Y., Zharkov, V.N., 2000. Martian crust: a modeling approach, Phys. Earth Plan. Int., 117, 1-4, 421-435.

Beattie, P., 1993. The generation of uranium series disequilibria by partial melting of spinel peridotite: constraints from partitioning studies, Earth Plan. Sci. Lett., 117, 3-4, 379-391.

Borg, L.E., Draper, D.S., 2003. A petrogenetic model for the origin and compositional variation of the Martian basaltic meteorites, Meteorit. Planet. Sci., 38, 1713-1731.

Brandon, A.D., Walker, R.J., Morgan, J.W., Goles, G.G., 2000. Re-Os isotopic evidence for early differentiation of the Martian mantle, Geochim. Cosmochim. Acta, 64, 4083-4095.

Breuer, D., Spohn, T., 2003, Early plate tectonics versus single-plate tectonics on Mars: Evidence from magnetic field history and crust evolution, J. Geophys. Res., 108, E7, 5072, doi:10.1029/2002JE001999.

Breuer D., Spohn, T., 2006. Viscosity of the Martian mantle and its initial temperature: Constraints from crust formation history and the evolution of the magnetic field Planet. Space Sci., 54, 153-169.

Buske, M., 2006. Three-dimensional thermal evolution models for the interior of Mars and Mercury, Ph.D Thesis, University of Göttingen

Basaltic Volcanism Study Project, 1981. Basaltic Volcanism on the Terrestrial Planets. Pergamon Press, New York.

Choblet, G., Sotin, C., 2000. 3D thermal convection with variable viscosity: can transient cooling be described by a quasi-static scaling law?, Phys. Earth Planet. Inter., 119, 3-4, 321-336.

Davaille, A., Jaupart, C., 1993. Transient high Rayleigh number thermal convection with large viscosity variations, J. Fluid Mech., 253, 141-166.

Deschamps, F., Sotin, C., 2001. Thermal convection in the outer shell of large icy satellites, J. Geophys. Res., 106, 5107-5121.

Dreibus, G., Wänke, H., 1987. Volatiles on earth and Mars - A comparison, Icarus, 71, 1987, 225-240, doi:10.1016/0019-1035(87)90148-5.

Elkins-Tanton, L.T., Hess, P.C., Parmentier, E.M., 2005. Possible formation of ancient crust on Mars through magma ocean processes. J. Geophys. Res. 110, E12S01, doi:10.1029/2005JE002480.

Foley, C.N., Wadhwa, M., Borg, L.E., Janney, P.E., Hines, R., Grove, T.L., 2005. The early differentiation history of Mars from ${ }^{182} \mathrm{~W}-{ }^{142} \mathrm{Nd}$ isotope systematics in the SNC meteorites, Geochim. Cosmochim. Acta, $69,2005,4557-4571$ 
Ghiorso, M.S., Hirschmann, M.M., Reiners, P.W., Kress, V.C., III, 2002. The pMELTS: A revision of MELTS for improved calculation of phase relations and major element partitioning related to partial melting of the mantle to $3 \mathrm{GPa}$, Geochem. Geophys. Geosyst., 3, 5, 1030, doi:10.1029/2002GC000217.

Grasset, O., Parmentier, E.M., 1998. Thermal convection in a volumetrically heated, infinite Prandtl number fluid with strongly temperature-dependent viscosity: Implications for planetary evolution, J. Geophys. Res., 103, 18171-18181.

Grott M., 2005. Late crustal growth on Mars: Evidence from lithospheric extension, Geophys. Res. Lett., 32, L23201, doi:10.1029/2005GL024492.

Grott, M., and D. Breuer (2008), The Evolution of the Martian Elastic Lithosphere and Implications for Crustal and Mantle Rheology Icarus, 193, 2, 503-515, doi:10.1016/j.icarus.2007.08.015.

Grott M., Breuer, D., 2008. Constraints on the radiogenic heat production rate in the Martian interior from viscous relaxation of crustal thickness variations, Geophys. Res. Lett., 35, 5, L05201, doi:10.1029/2007GL033021.

Grott M., Breuer, D., 2009. Implications of large elastic thicknesses for the composition and current thermal state of Mars Icarus, 201, 2, 540-548, doi:10.1016/j.icarus.2009.01.020.

Grott M., Breuer, D., 2010 On the spatial variability of the Martian elastic lithosphere thickness: Evidence for mantle plumes?, J. Geophys. Res., 115, E3, E03005, doi:10.1029/2009JE003456.

Harder, H., Christensen, U.R., 1996. A one-plume model of martian mantle convection, Nature, 380, 507-509, doi:10.1038/380507a0.

Hart, S.R., Dunn, T., 1993. Experimental cpx/melt partitioning of 24 trace elements, Contrib. Mineral. Petrol., 113, 1, 1-8.

Hauber, E., Bleacher, J., Gwinner, K., Williams, D., Greeley, R., 2009. The topography and morphology of low shields and associated landforms of plains volcanism in the Tharsis region of Mars, J. Volcan. Geoth. Res., 185, 1-2, 69-95.

Hauck, S.A., Phillips, R.J., 2002. Thermal and crustal evolution of Mars, J. Geophys. Res., 107, E7, 5052, doi:10.1029/2001JE001801.

Hauri, E.E., Wagner, T.P., Grove, T.L., 1994. Experimental and natural partitioning of Th, U, Pb and other trace elements between garnet, clinopyroxene and basaltic melts, Chem. Geol., 117, 1-4, 149-166.

Halliday, A.N., Wanke, H., Birck, J.-L., Clayton, R.N., 2001. The Accretion, Composition and Early Differentiation of Mars, Space Sci. Rev., 96, 197-230, 2001.

Hartmann, W.K., Malin, M., McEwen, A., Carr, M., Soderblom, L., Thomas, P., Danielson, E., James, P., Veverka, J., 1999. Evidence for recent volcanism on Mars from crater counts, Nature, 397, 6720, 586, doi:10.1038/17545.

Hartmann, W.K., Berman, D.C., 2000. Elysium Planitia lava flows: Crater count chronology and geological 
implications, J. Geophys. Res., 105, E6, 15011-15026, doi:10.1029/1999JE001189.

Herzberg, C., Raterror, P., Zhang, J., 2000. New experimental observations on the anhydrous solidus for peridotite KLB-1, Geochem. Geophys. Geosyst. 1, 1051.

Hirschmann, M.M., 2000. Mantle solidus: Experimental constraints and the effects of peridotite composition, Geochem. Geophys. Geosyst., 1, 1042, doi:10.1029/2000GC000070.

Hirth, G., Kohlstedt, D.L., 1996. Water in the oceanic upper mantle: implications for rheology, melt extraction and the evolution of the lithosphere Earth Plan. Sci. Lett., 144, 1-2, 93-108, doi:10.1016/0012821X(96)00154-9.

Iwamori, H.G., McKenzie, D., Takahashi, E., 1995. Melt generation by isentropic mantle upwelling. Earth Planet. Sci. Lett., 134, 253-266.

Jagoutz, E., 1991. Chronology of SNC meteorites. Space Sci. Rev., 56, 13-22.

Johnson, M.C., Rutherford, M.J., Hess, P.C., 1991. Chassigny petrogenesis - Melt compositions, intensive parameters, and water contents of Martian (?) magmas, Geochim. Cosmochim. Acta, 55, 349-366, doi:10.1016/0016-7037(91)90423-3.

Karato, S.-I., Wu, P., 1993. Rheology of the Upper Mantle: A Synthesis, Science, 260, 771-778, doi:10.1126/science.260.5109.771.

Katz, R.F., Spiegelman, M., Langmuir, C.H., 2003. A new parameterization of hydrous mantle melting, Geochem. Geophys. Geosys., 4, 9, 1, CiteID 1073, doi:10,1029/2002GC000433.

Keller, T., Tackley, P.J., 2009. Towards self-consistent modeling of the martian dichotomy: The influence of one-ridge convection on crustal thickness distribution, Icarus, 202, 2, 429-443, doi:10.1016/j.icarus.2009.03.029.

Kiefer, W.S., Li., Q., 2009. Mantle convection controls the observed lateral variations in lithospheric thickness on present day Mars, Geophys. Res. Lett., 36, L18203, doi:10.1029/2009GL039827.

Fraeman, A.A., Korenaga, J., 2010. The influence of mantle melting on the evolution of Mars, Icarus, 210(1), 43-57, doi:10.1016/j.icarus.2010.06.030.

Lee, D.C., Halliday, A.N., 1997. Core formation on Mars and differentiated asteroids, Nature, 388, 6645, 854-857.

Li, Q., Kiefer, W.S., 2007. Mantle convection and magma production on present day Mars: Effects of temperature-dependent rheology, Geophys. Res. Lett., 34, 16, L16203, doi:10.1029/2007GL030544.

Lillis, R.J., Dufek, J., Bleacher, J.E., Manga, M., 2009. Demagnetization of crust by magmatic intrusion near the Arsia Mons volcano: Magnetic and thermal implications for the development of the Tharsis province, Mars, J. Volcan. Geoth. Res., 185, 1-2, 123-138.

Lodders, K., Fegley, B., 1997. An Oxygen Isotope Model for the Composition of Mars, Icarus, 126, 2, 373-394, doi:10.1006/icar.1996.5653. 
McDonough, W.F., Sun, S.S., 1989. The composition of the Earth, Chem. Geol., 120, 223-253.

McGovern, P.J., Solomon, S.C., Smith, D.E., Zuber, M.T., Simons, M., Wieczorek, M.A., Phillips, R.J., Neumann, G.A., Aharonson, O., Head, J.W., 2002. Localized gravity/topography admittance and correlation spectra on Mars: Implications for regional and global evolution, J. Geophys. Res., 107, 5136, doi:10.1029/2002JE001854.

McGovern, P.J., Solomon, S.C., Smith, D.E., Zuber, M.T., Simons, M., Wieczorek, M.A., Phillips, R.J., Neumann, G.A., Aharonson, O., Head, J.W., 2004. Correction to "Localized gravity/topography admittance and correlation spectra on Mars: Implications for regional and global evolution", J. Geophys. Res., 109, E07007.

McSween, H.Y., Grove, T.L., Lentz, R.C.F., Dann, J.C. , Holzheid, A.H., Riciputi, L.R., Ryan, J.G., 2001.

Geochemical evidence for magmatic water within Mars from pyroxenes in the Shergotty meteorite, Nature, 409, 487-490, doi:10.1038/35054011.

Médard, E., Grove, T.L., 2006. Early hydrous melting and degassing of the Martian interior, J. Geophys. Res., 111, E11, E11003, doi:10.1029/2006JE002742.

Mei, S., Kohlstedt, D.L., 2000a. Influence of water on plastic deformation of olivine aggregates 1. Diffusion creep regime J. Geophys. Res., 105, B9, 21457-21470, doi:10.1029/2000JB900179.

Mei, S., Kohlstedt, D.L., 2000b. Influence of water on plastic deformation of olivine aggregates 2. Dislocation creep regime, J. Geophys. Res., 105, B9, 21471-21482, doi:10.1029/2000JB900180.

Mohit, P.S., Phillips, R.J., 2007. Viscous relaxation on early Mars: A study of ancient impact basins, Geophys. Res. Lett., 34, 21, L21204, doi:10.1029/2007GL031252

Neukum, G., Jaumann, R., Hoffmann, H., Hauber, E., Head, J.W., Basilevsky, A.T., Ivanov, B.A., Werner, A.C., van Gasselt, S., Murray, J.B., McCord, T., and the HRSC Co-Investigator Team, 2004. Recent and episodic volcanic and glacial activity on Mars revealed by the High Resolution Stereo Camera, Nature, 432, 7020, 971-979, doi:10.1038/nature03231.

Nimmo, F., Stevenson, D.J., 2000. Influence of early plate tectonics on the thermal evolution and magnetic field of Mars, J. Geophys. Res., 105, E5, 11969-11980, doi:10.1029/1999JE001216.

Nimmo, F., Stevenson, D.J., 2001. Estimates of Martian crustal thickness from viscous relaxation of topography, J. Geophys. Res., 106, 5085-5098.

Nimmo, F., Tanaka, K., 2005. Early Crustal Evolution of Mars, A.R.E.P.S., 33, 133-161,

Norman, M.D., 1999. The composition and thickness of the crust of Mars estimated from REE and Nd isotopic compositions of Martian meteorites, Meteor. Planet. Sci., 34, 439-449.

Norman, M.D., 2002. Thickness and Composition of the Martian Crust Revisited: Implications of an Ultradepleted Mantle with a Nd Isotopic Composition Like that of QUE94201, Proc. Lunar Planet. Sci. Conf. $33^{r d}$, abstract 1174 . 
Nyquist, L.E., Bogard, D.D., Shih, C.-Y., Greshake, A., Stöffler, D., Eugster, O., 2001. Ages and Geologic Histories of Martian Meteorites, Sp. Sci. Rev., 96, 105-164.

Maaløe, S., 2004. The solidus of harzburgite to $3 \mathrm{GPa}$ pressure: the compositions of primary abyssal tholeiite Miner. Petr., 81, 1-2, 1-17, doi:10.1007/s00710-004-0028-6.

McKenzie, D., Bickle, M.J., 1988. The volume and composition of melt generated by extension of the lithosphere, J. Petrol., 29, 625-679.

O'Neill, C., Lenardic, A., Jellinek, A.M., Kiefer, W.S., 2007. Melt propagation and volcanism in mantle convection simulations, with applications for Martian volcanic and atmospheric evolution, J. Geophys. Res., 112, E7, E07003, doi:10.1029/2006JE002799

Papike, J.J., Karner, J.M., Shearer, C.K., Burger, P.V., 2009. Silicate mineralogy of martian meteorites, Geoch. Cosmoch. Acta, 73, 2009, 7443-7485.

Phillips, R.J., Zuber, M.T., Solomon, S.C., Golombek, M.P., Jakosky, B.M., Banerdt, W.B., Williams, R.M., Hynek,B., Aharonson, O., Hauck, S.A., 2001. Ancient geodynamics and global-scale hydrology on Mars, Science, 291, 2587-2591.

Phillips, R.J., et al., 2008. Mars north polar deposits: Stratigraphy, age, and geodynamical response, Science, 320, 1182-1185, oi:10.1126/science.1157546.

Ohtani, E., Suzuki, A., Kato, T, 1998. Flotation of olivine and diamond in mantle melt at high pressure: Implications for fractionation in the deep mantle and ultradeep origin of diamond, in Properties of Earth and Planetary Materials at High Pressure and Temperature Geophys. Monogr.Ser., 101, edited by M. H. Manghnani and T. Yagi, 227-239, AGU, Washington, D.C.

Parmentier, E.M., Zuber, M.T., 2007. Early eyolution of Mars with mantle compositional stratification or hydrothermal crustal cooling, J. Geophys. Res., 112, E2, E02007, doi:10.1029/2005JE002626.

Suzuki, A., Ohtani, E., Kato, T., 1998. Density and thermal expansion of a peridotite melt at high pressure Phys. Earth Plan. Int., 107, 1-3, 53-61.

Richter, F.M., 1978. Mantle convection models, Annu. Rev. Earth. Planet. Sci., 6, 9.

Reese, C. C., Solomatov, V.S., Moresi, L.-N., 1998. Heat transport efficiency for stagnant lid convection with dislocation viscosity: Application to Mars and Venus, J. Geophys. Res., 103, E6, 13643-13658, doi:10.1029/98JE01047.

Reese, C.C., Solomatov, V.S., Baumgardner, J.R., 2005. Scaling laws for time-dependent stagnant lid convection in a spherical shell, Phys. Earth Planet. Int., 149, 3-4, 361-370, doi:10.1016/j.pepi.2004.11.004.

Ruiz, J., Tejero, R., McGovern, P.J., Evidence for a differentiated crust in Solis Planum, Mars, from lithospheric strength and heat flow, Icarus, 180, 2, 308-313, doi:10.1016/j.icarus.2005.09.010.

Ruiz, J., Williams, J.-P., Dohm, J.M., Fernández, C., López, V., 2009. Ancient heat flow and crustal thickness at Warrego rise, Thaumasia highlands, Mars: Implications for a stratified crust, Icarus, 203, 1, 
47-57, doi:10.1016/j.icarus.2009.05.008.

Schubert, G., Cassen, P., Young, R.E., 1979. Subsolidus convective cooling histories of terrestrial planets, Icarus, 38, 192-211, doi:10.1016/0019-1035(79)90178-7.

Schubert, G., Spohn, T., 1990, Thermal history of Mars and the sulfur content of its core, J. Geophys. Res., 95, 14095-14104.

Schumacher, S., Breuer, D., 2006. Influence of a variable thermal conductivity on the thermochemical evolution of Mars, J. Geophys. Res., 111, E2, E02006, doi:10.1029/2005JE002429.

Schumacher, S., Breuer, D., 2007. An alternative mechanism for recent volcanism on Mars, Geophys. Res. Lett., 34, 14, L14202, doi:10.1029/2007GL030083.

Solomatov, V.S., Moresi, L.N, 1997. Three regimes of mantle convection with non-Newtonian viscosity and stagnant lid convection on the terrestrial planets, Geophys. Res. Lett., 24, 15, 1907-1910, doi:10.1029/97GL01682.

Solomatov, V.S., Moresi, L.N, 2000. Scaling of time-dependent stagnant lid convection: Application to small-scale convection on Earth and other terrestrial planets. Geophys. Res. Lett., 105, B9, $21795-21817$.

Spohn, T., 1991. Mantle differentiation and thermal evolution of Mars, Mercury, and Venus, Icarus, 90, 222-236, doi:10.1016/0019-1035(91)90103-Z.

Spohn, T., Schubert, G., 1982. Modes of mantle convection and the removal of heat from the earth's interior, J. Geophys. Res., 87, 4682-4696.

Spohn, T., Schubert, G., 1990. Thermal history of Mars and the sulfur content of its core, J. Geophys. Res., 95, 14095-14104, doi:10.1029/JB095iB09p14095.

Sevenson, D.J., Spohn, T., Schubert, G., 1983. Magnetism and thermal evolution of the terrestrial planets. Icarus, 54, 466-489, doi:10.1016/0019-1035(83)90241-5.

Stevenson, D.J., 2001. Mars core and magnetism, Nature, 412, 214-219.

Takahashi, E., 1990. Speculations on the Archean mantle: Missing link between komatiite and depleted garnet peridotite, J. Geophys. Res., 95, B10, 15941-15954.

Taylor, G.J., Boynton, W., Brückner, J., Wänke, H., Dreibus, G., Kerry, K., Keller, J., Reedy, R., Evans, L., Starr, R., Squyres, S., Karunatillake, S., Gasnault, O., Maurice, S., d’Uston, C., Englert, P., Dohm, J., Baker, V., Hamara, D., Janes, D., Sprague, A., Kim K., Drake, D., 2006. Bulk composition and early differentiation of Mars, J. Geophys. Res., 111, E3, E03S10, doi:10.1029/2005JE002645.

Treiman, A.H., Drake, M.J., Janssens, M.-J., Wolf, R., Ebihara, M., 1986. Core formation in the earth and shergottite parent body (SPB) - Chemical evidence from basalts, Geochim. Cosmochim. Acta, 50, 1071-1091, doi:10.1016/0016-7037(86)90389-3.

Turcotte, D.L. and G. Schubert, 2002. Geodynamics, 2nd ed., 456 pp., Cambridge Univ. Press, New York. Wänke, H., Dreibus, G., 1994. Chemistry and accretion history of Mars, Phil. Trans. R. Soc. London, A349, 
$285-293$.

Werner, S.C., 2009. The global martian volcanic evolutionary history Icarus, 201, 1, 44-68, doi:10.1016/j.icarus.2008.12.019.

Wieczorek, M.A., Zuber, M.T., 2004. Thickness of the Martian crust: Improved constraints from geoid-totopography ratios, J. Geophys. Res., 109, E1, E01009, doi:10.1029/2003JE002153.

Zhang, J., Herzberg, C., 1994. Melting experiments on anhydrous peridotite KLB-1 from 5.0 to 22.5 GPa, J. Geophys. Res., 99, B9, 17,729-17,742, doi:10.1029/94JB01406.

Zhao, Y.-H., Zimmerman, M.E., Kohlstedt, D.L., 2009. Effect of iron content on the creep behavior of olivine: 1. Anhydrous conditions, Earth Plan. Sci. Lett., 287, 1-2, 229-240, doi:10.1016/j.epsl.2009.08.006. 
Figure 1 Peridotite solidus temperature as a function of pressure for six different parameterizations. Note that the fits by Herzberg et al. (2000) and Zhang and Herzberg (1994) are valid only for pressures above 2.5 and $5 \mathrm{GPa}$, respectively.

Figure 2 (a) Stagnant lid thickness and crustal thickness as a function of time for $T_{m}^{0}=1650 \mathrm{~K}, D_{c r}^{0}=30 \mathrm{~km}$, and a reference viscosity of $\eta_{0}=10^{18}$ Pas. The model does not include dehydration stiffening of the mantle upon water extraction. When the stagnant lid thickness $D_{l}$ equals the crustal thickness, crustal erosion sets in and crustal growth is limited by $D_{l}$. (b) Upper mantle temperature $T_{m}$, core temperature $T_{c}$ and lower crustal temperature $T_{c r}$ as a function of time for the same model. (c) Heat flux out of the mantle into the stagnant lid $q_{l}$, out of the core $q_{c}$, and surface heat flux $q_{s}$ as a function of time for the same model. (d) Normalized bulk water content $X_{\mathrm{H}_{2} \mathrm{O}}$ as a function of time for the same model. (e) Crust production rate as a function of time. (f) Location and extent of the meltzone (shaded) as a function of time. As a reference, the extent of the stagnant lid (solid line) and the crustal thickness (dashed line) are also given.

Figure 3 (a) Crustal thickness $D_{c r}$ as a function of time for different initial mantle temperatures $T_{m}^{0}$ and a reference viscosity of $\eta_{0}=10^{19}$ Pas. No primordial crust is assumed. (b) Crustal thickness $D_{c r}$ as a function of time for different reference viscosities $\eta_{0}$ and an initial upper mantle temperature $T_{m}^{0}$ of $1700 \mathrm{~K}$. No primordial crust is assumed.

Figure 4 (a) Eroded crustal fraction in percent of the present day crustal thickness as a function of initial upper mantle temperature $T_{m}^{0}$ for different reference viscosities $\eta_{0}$. No primordial crust is assumed. (b) Same as (a), but with a primordial crust of $30 \mathrm{~km}$ thickness.

Figure 5 (a) Fraction of crust in percent produced before 500 Myr as a function of initial upper mantle temperature $T_{m}^{0}$ for different reference viscosities $\eta_{0}$. No primordial crust is assumed. Values greater than $100 \%$ indicate models with vigorous crust production before 500 Myr which is eroded afterwards. The dashed line indicates the lower limit of the admissible range. (b) Same as (a), but including a primordial crust of $30 \mathrm{~km}$ thickness. (c) Present day crustal thickness as a function of initial upper mantle temperature $T_{m}^{0}$ for different reference viscosities $\eta_{0}$. No primordial crust is assumed. Dashed lines indicate the admissible range of crustal thicknesses. (d) Same as (c), but including a primordial 
crust of $30 \mathrm{~km}$ thickness.

Figure 6 (a) Minimum present day temperature difference between the solidus of peridotite and an uprising mantle plume as a function of initial upper mantle temperature $T_{m}^{0}$ for different reference viscosities $\eta_{0}$. No primordial crust is assumed. (b) Distance which mantle plumes would have to penetrate into the stagnant lid from below to initiate decompression melting in percent of the stagnant lid thickness as a function of initial upper mantle temperature $T_{m}^{0}$ for different reference viscosities $\eta_{0}$. Melting is assumed to take place in a region of locally thickened, thermally insulating crust, such that plume temperatures are increased by $100 \mathrm{~K}$. No primordial crust is assumed.

Figure 7 (a) Ratio of measured (Taylor et al., 2006) to calculated abundance of potassium in the Martian crust. No primordial crust is assumed. Dashed lines indicate the spatial standard deviation of the measurements. (b) Same as (a), but including a primordial crust of $30 \mathrm{~km}$ thickness.

Figure 8 (a) Stagnant lid thickness and crustal thickness as a function of time for the nominal model including dehydration stiffening with $T_{m}^{0}=1650 \mathrm{~K}, D_{c r}^{0}=30 \mathrm{~km}$, and $\eta_{\text {wet }}=10^{18}$ Pas. (b) Upper mantle temperature $T_{m}$, core temperature $T_{c}$ and lower crustal temperature $T_{c r}$ as a function of time for the same model. (c) Heat flux out of the mantle into the stagnant lid $q_{l}$, out of the core $q_{c}$, and surface heat flux $q_{s}$ as a function of time for the same model. (d) Normalized bulk water content $X_{\mathrm{H}_{2} \mathrm{O}}$ as a function of time for the same model. (e) Crust production rate as a function of time. (f) Location and extent of the meltzone (shaded) as a function of time. As a reference, the extent of the stagnant lid (solid line) and the crustal thickness (dashed line) are also given.

Figure 9 (a) Ratio of measured (Taylor et al., 2006) to calculated abundance of potassium in the Martian crust for models with dehydration stiffening. The dash-dotted line represents a model without a primordial crust and solid lines represent models with a primordial crustal thickness of $D_{c r}^{0}=30 \mathrm{~km}$. The enrichment factor $\Lambda$ of heat producing elements in the primordial crust has been varied. Also, the corresponding fraction $f_{p}$ of radioactive elements in a primordial crust of $D_{c r}^{0}=30 \mathrm{~km}$ thickness with respect to the mantle is given. The two horizontal lines mark the limit given by the spatial standard derivation of 
measurements of K on the Martian surface (Taylor et al., 2006).

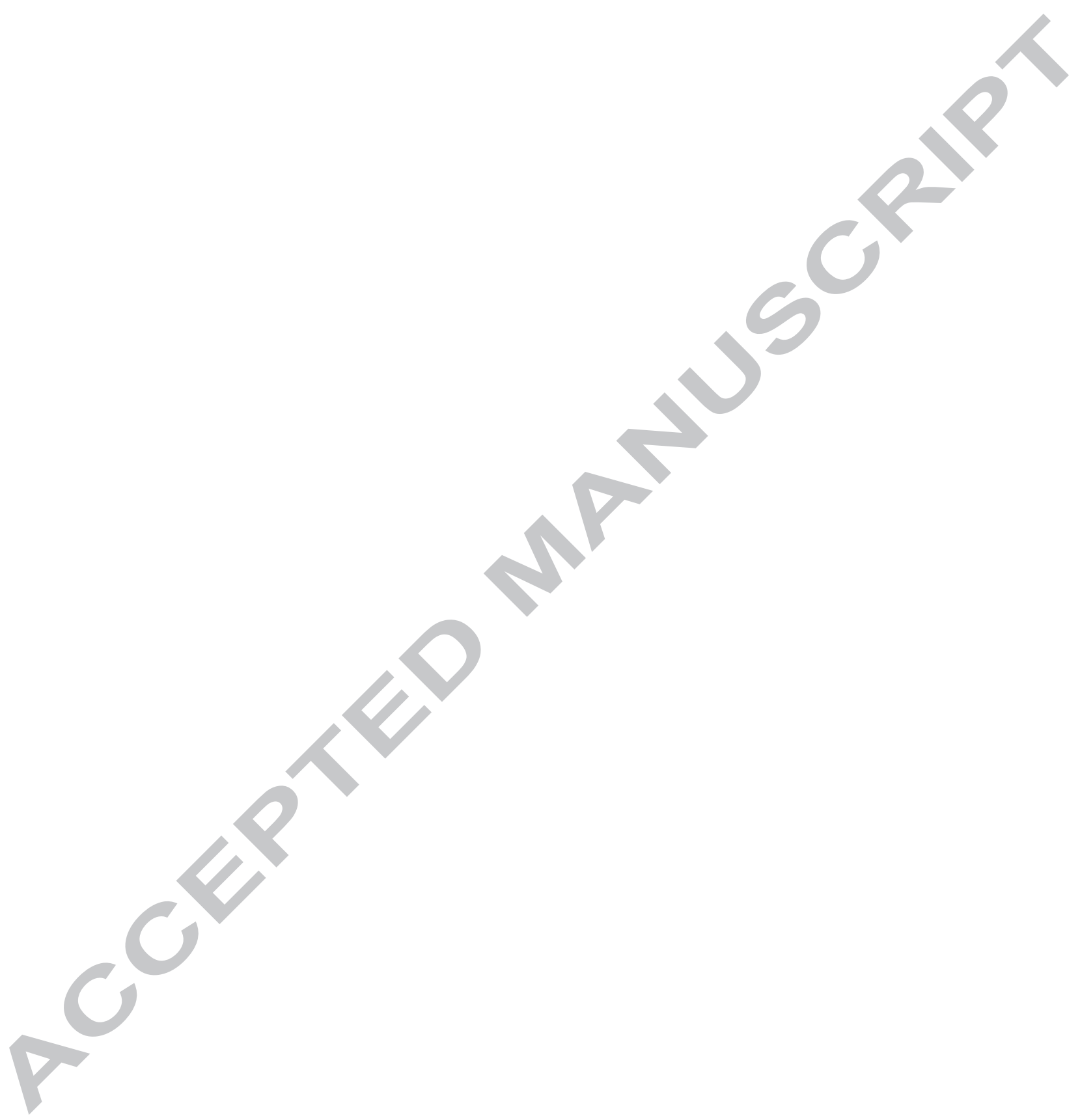




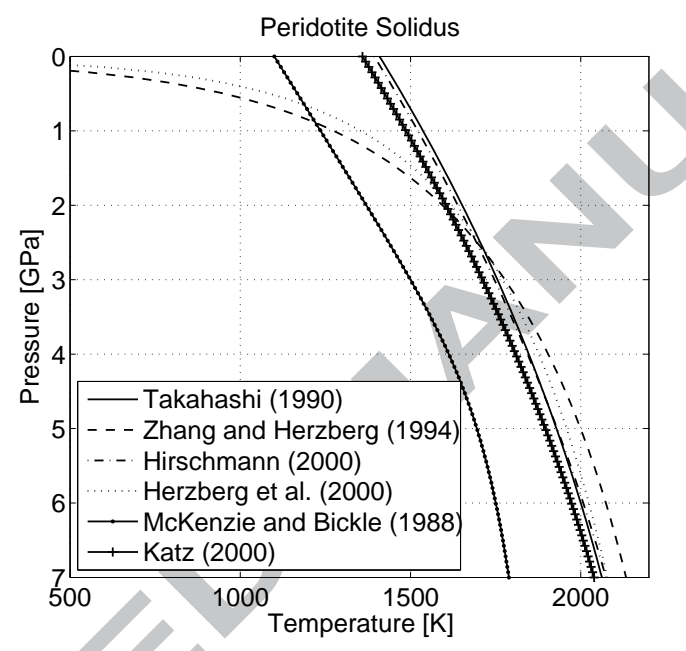

Figure 1: 


\section{ACCEPTED MANUSCRIPT}
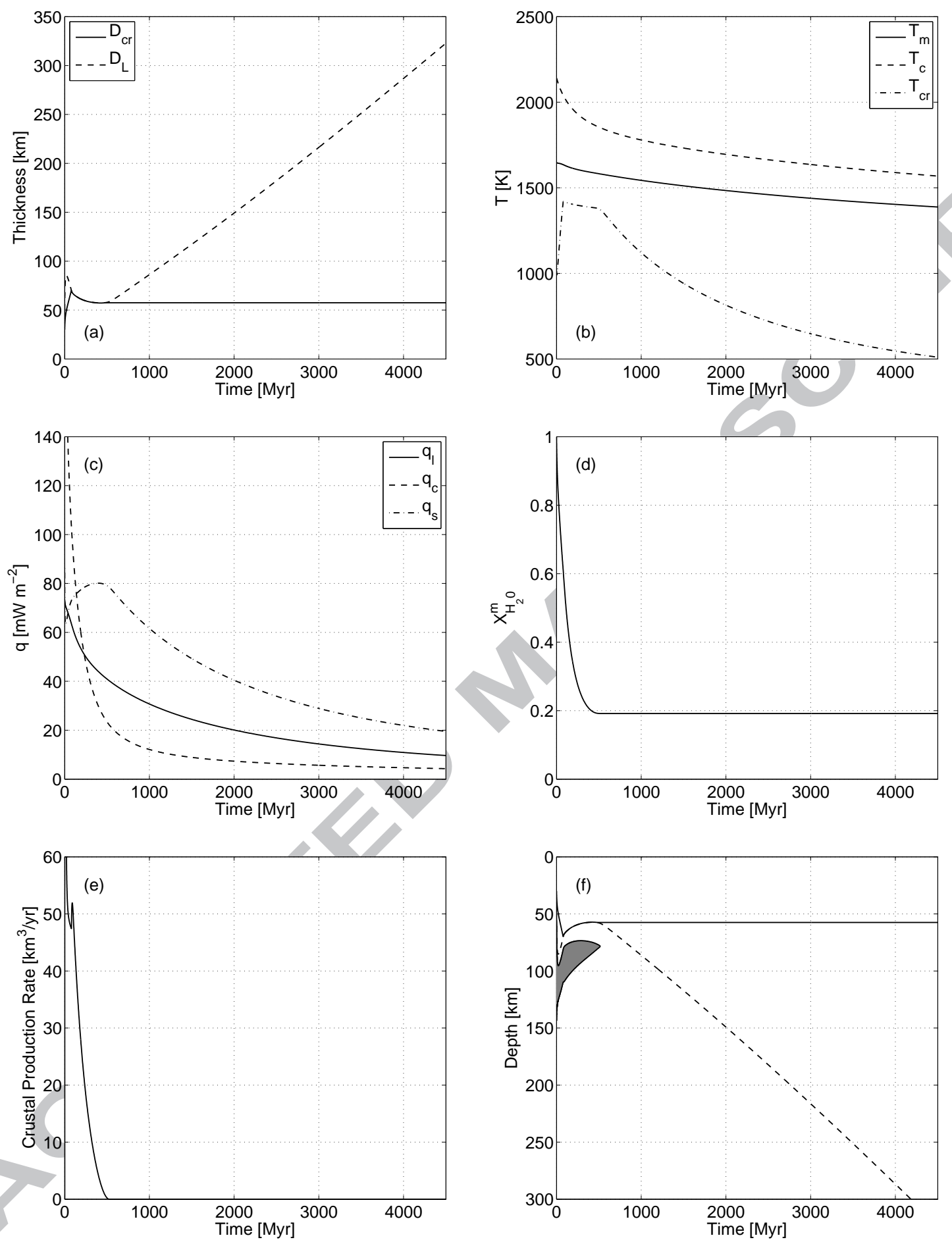

Figure 2: 

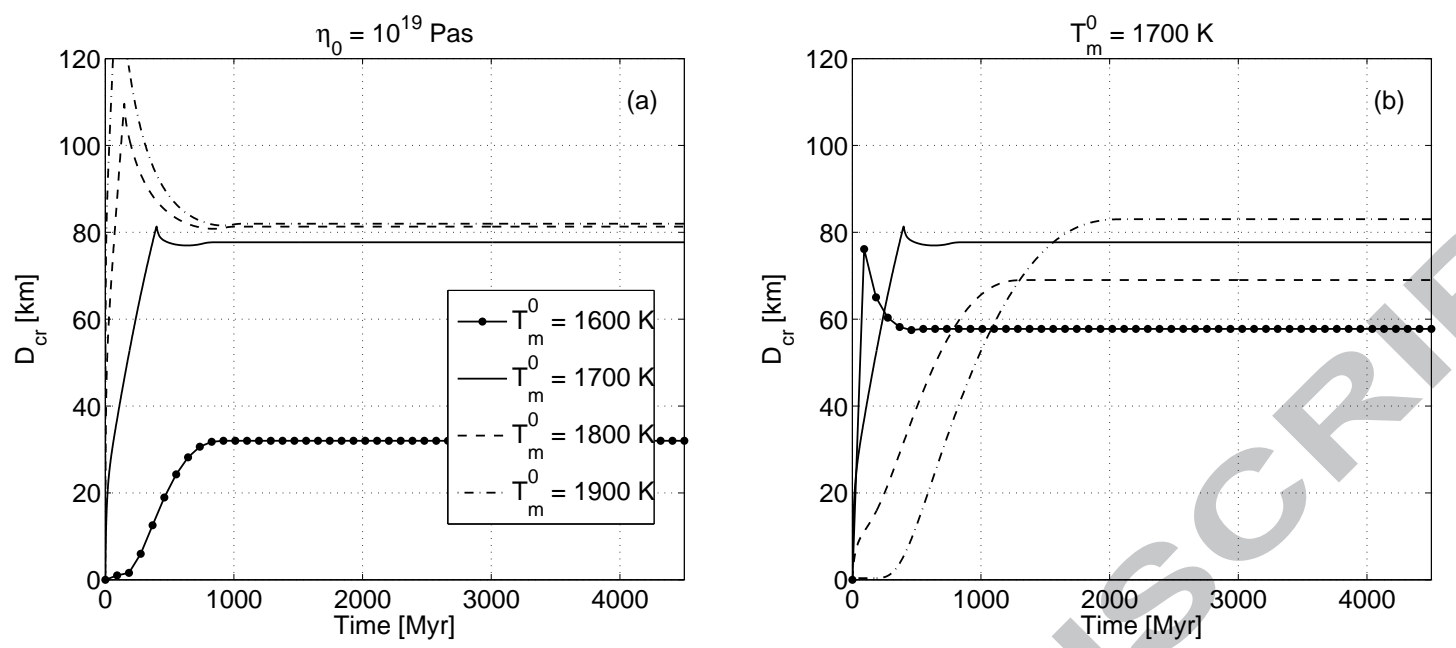

Figure 3:
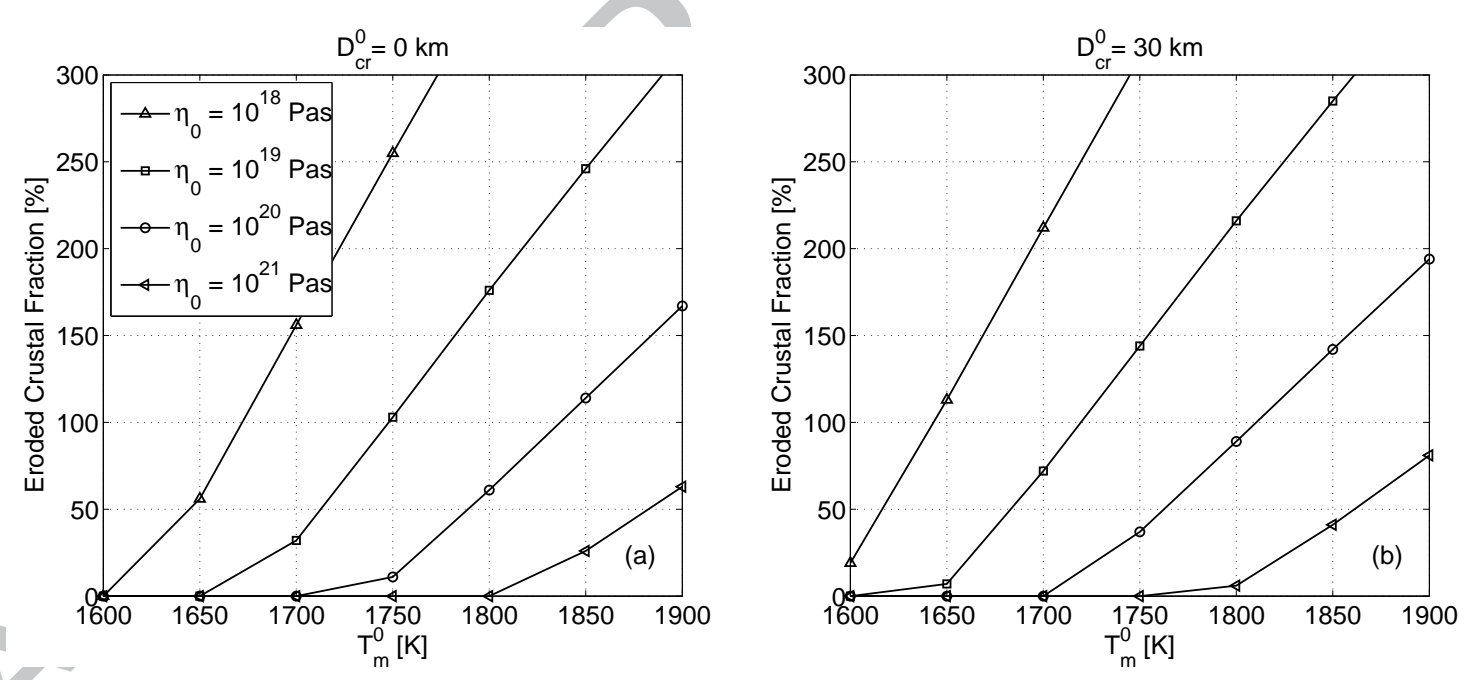

Figure 4: 

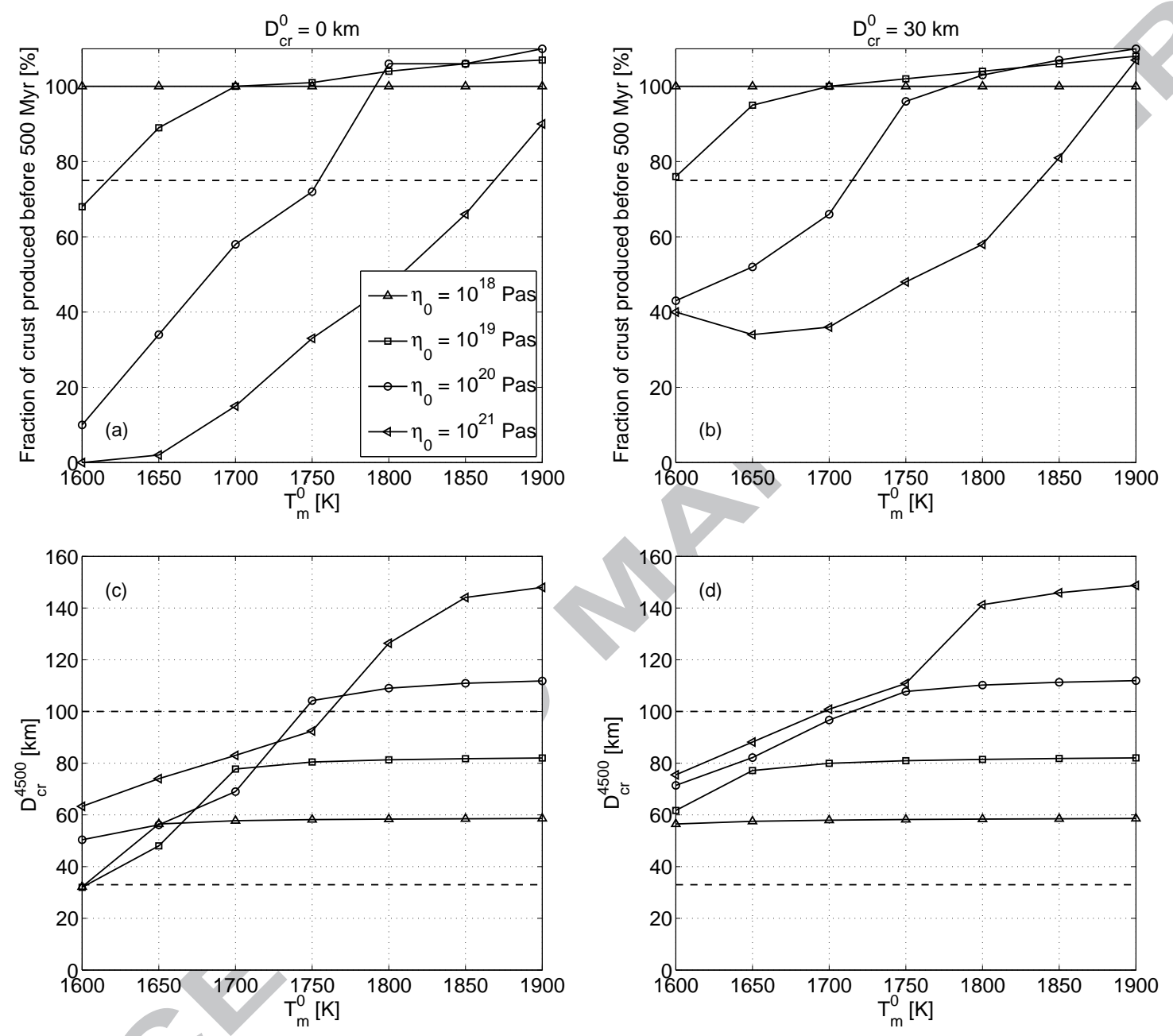

Figure 5: 


\section{ACCEPTED MANUSCRIPT}
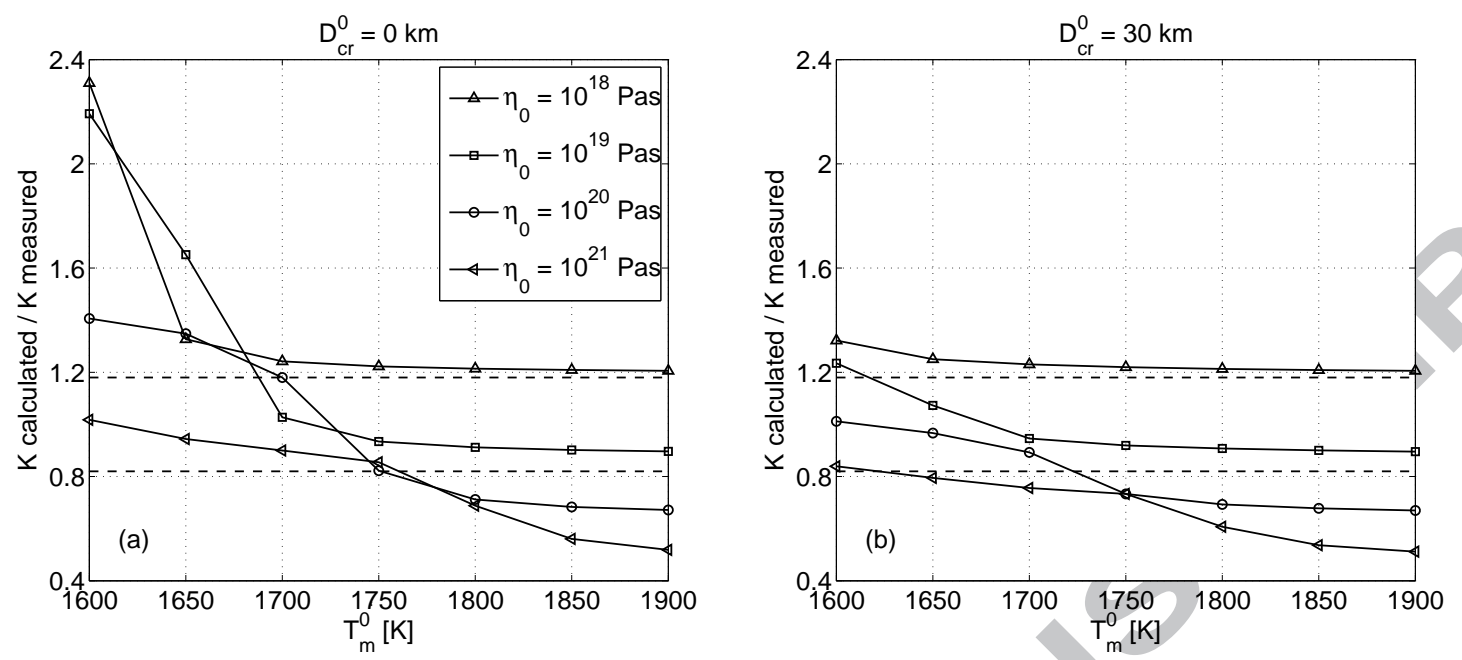

Figure 6:
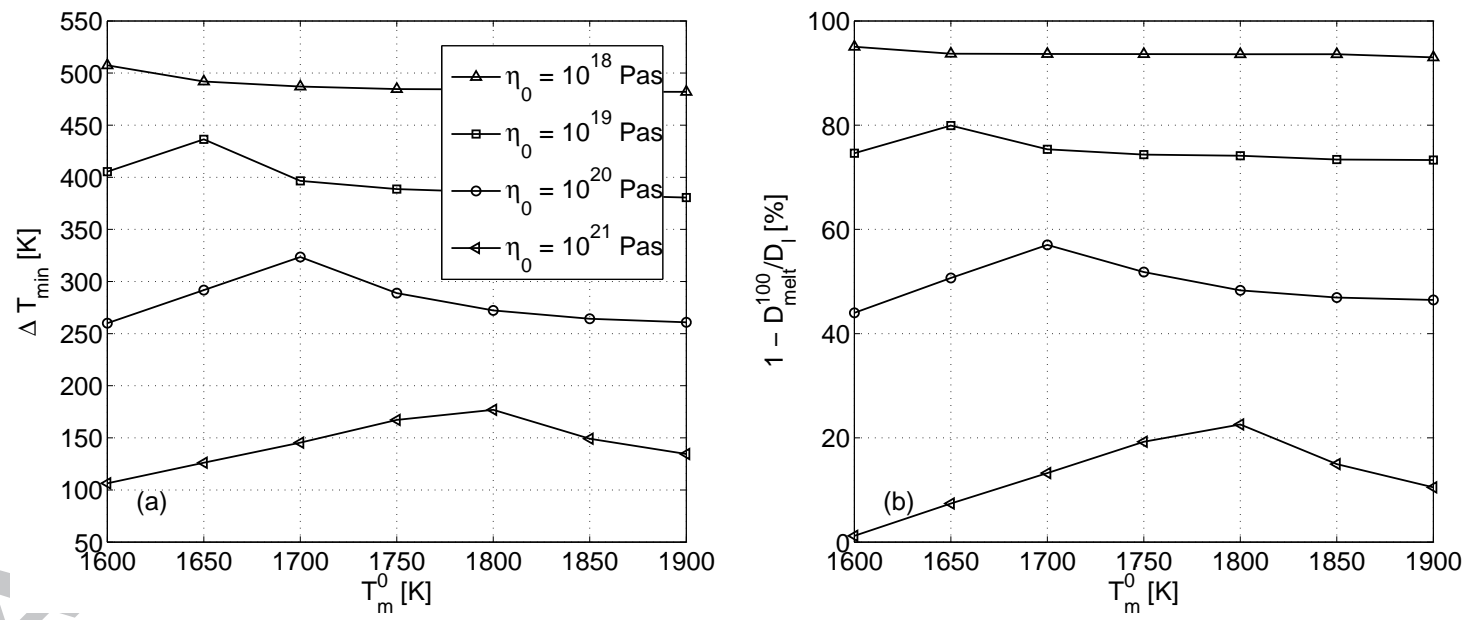

Figure 7: 


\section{ACCEPTED MANUSCRIPT}
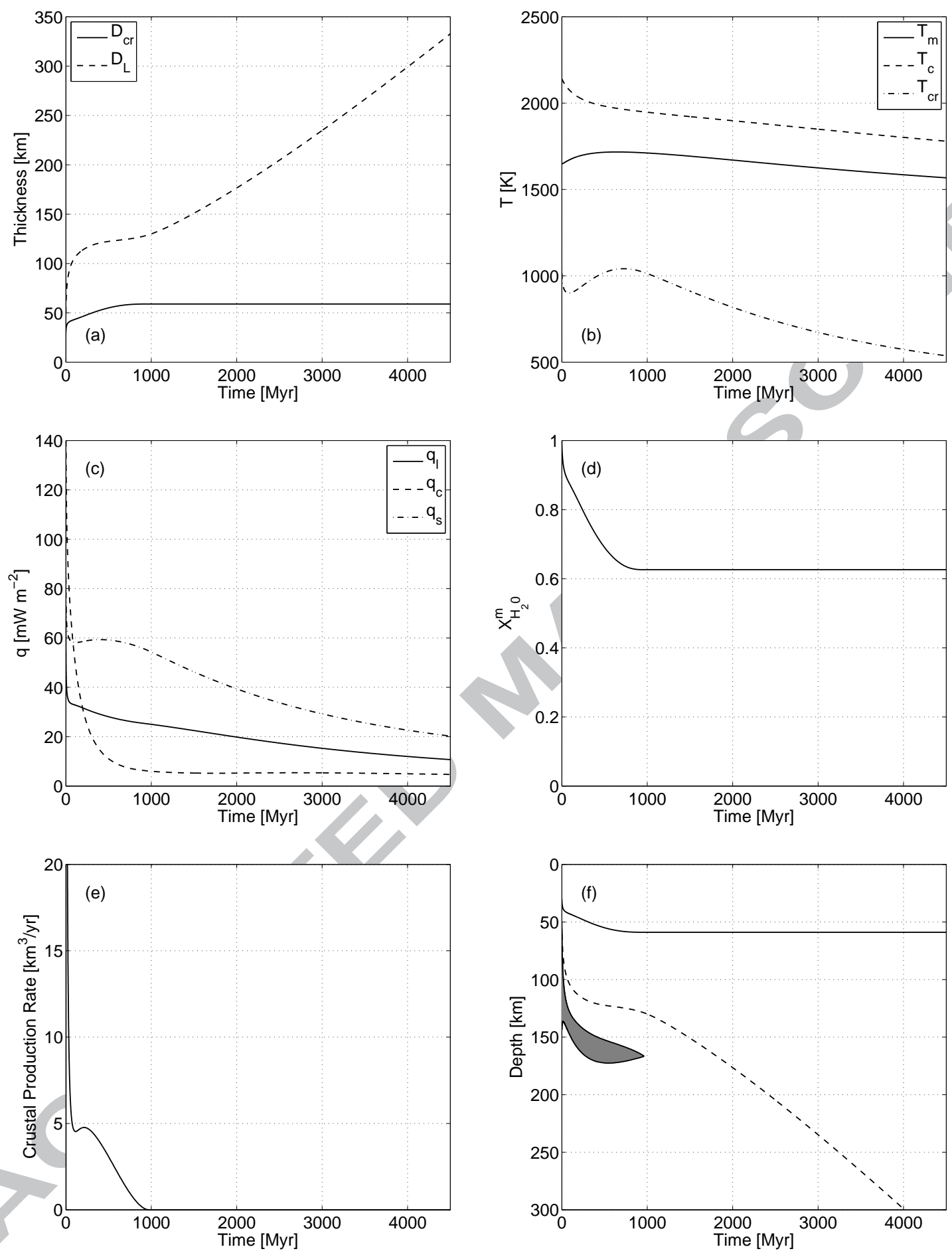

Figure 8: 


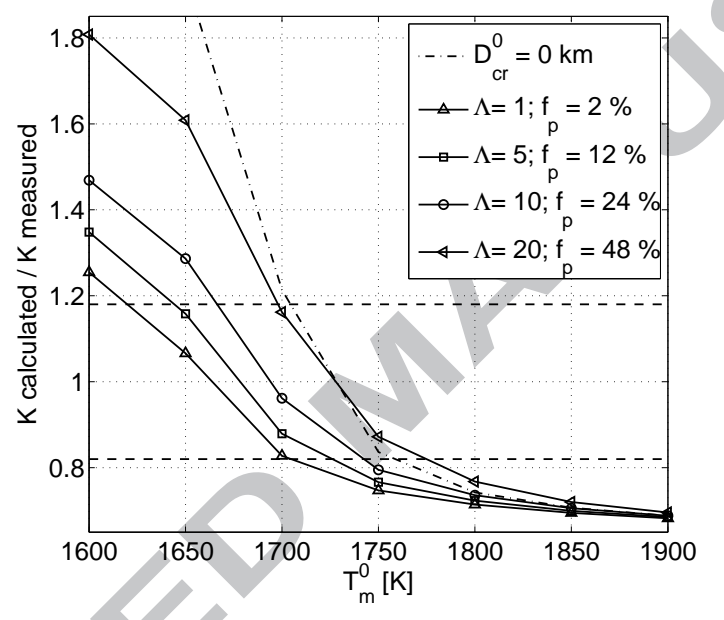

Figure 9: 
Table 1: Parameters used in this study.

\begin{tabular}{|c|c|c|c|}
\hline Variable & Physical Meaning & Value & Units \\
\hline$R_{p}$ & Planetary radius & $3390 \times 10^{3}$ & $\mathrm{~m}$ \\
\hline$R_{c}$ & Core radius & $1550 \times 10^{3}$ & $\mathrm{~m}$ \\
\hline$g$ & Surface gravity & 3.7 & $\mathrm{~m} \mathrm{~s}^{-2}$ \\
\hline$T_{s}$ & Surface temperature & 220 & $\mathrm{~K}$ \\
\hline$\Delta T_{c m}$ & Initial core-mantle temperature difference & 300 & \\
\hline$\rho_{c r}$ & Crustal density & 2900 & $\mathrm{~kg} \mathrm{~m} \mathrm{~m}^{-3}$ \\
\hline$\rho_{m}$ & Mantle density & 3500 & $\mathrm{~kg} \mathrm{~m}^{-3}$ \\
\hline$\rho_{c}$ & Core density & 7200 & $\mathrm{~kg} \mathrm{~m} \mathrm{~m}^{-3}$ \\
\hline$c_{c r}$ & Magma heat capacity & & $\mathrm{J} \mathrm{kg}^{-1} \mathrm{~K}^{-1}$ \\
\hline$c_{m}$ & Mantle heat capacity & 1142 & $\mathrm{~J} \mathrm{~kg}^{-1} \mathrm{~K}^{-1}$ \\
\hline$c_{c}$ & Core heat capacity & 840 & $\mathrm{~J} \mathrm{~kg}^{-1} \mathrm{~K}^{-1}$ \\
\hline$\epsilon_{m}$ & Ratio of mean and upper mantle temperature & 1.0 & \\
\hline$\epsilon_{c}$ & Ratio of mean and upper core temperature & 1.1 & \\
\hline$R$ & Gas constant & 8.3144 & $\mathrm{~J} \mathrm{~K}^{-1} \mathrm{~mol}^{-1}$ \\
\hline$T_{r e f}$ & Reference temperatu & 1600 & $\mathrm{~K}$ \\
\hline$A$ & Activation Energy & $3 \times 10^{5}$ & $\mathrm{~J} \mathrm{~mol}^{-1}$ \\
\hline$k_{c r}$ & Crust thermal conductivity & 3 & $\mathrm{~W} \mathrm{~m}^{-1} \mathrm{~K}^{-1}$ \\
\hline$k_{m}$ & Mantle thermal conductivity & 4 & $\mathrm{~W} \mathrm{~m} \mathrm{~m}^{-1} \mathrm{~K}^{-1}$ \\
\hline$\kappa$ & Mantle thermal diffusivity & $10^{-6}$ & $\mathrm{~m}^{2} \mathrm{~s}^{-1}$ \\
\hline$\alpha$ & Thermal expansion coefficient & $2 \times 10^{-5}$ & $\mathrm{~K}^{-1}$ \\
\hline$R a_{\text {crit }}$ & Critical Rayleigh number & 450 & \\
\hline$L$ & Latent heat of melting & $6 \times 10^{5}$ & $\mathrm{~J} \mathrm{~kg}^{-1}$ \\
\hline$u_{0}$ & Convection speed scale & $2 \times 10^{-12}$ & $\mathrm{~m} \mathrm{~s}^{-1}$ \\
\hline$X_{H 2 O}^{0}$ & Initial mantle water content & 100 & ppm \\
\hline$D_{l 0}$ & Initial stagnant lid thickness & 50 & $\mathrm{~km}$ \\
\hline
\end{tabular}


Table 2: Results for models including dehydration stiffening for different initial upper mantle temperatures $T_{m}^{0}$ and primordial crustal thicknesses $D_{c r}^{0}$. For models including a primordial crust, the crustal enrichment factor $\Lambda$ is also given. For each model, the final crustal thickness $D_{c r}^{4500}$, the fraction $f_{c r}^{500}$ of crust produced before $500 \mathrm{Myr}$, the minimum temperature difference $\Delta T_{\text {min }}$ between the peridotite solidus and uprising mantle plumes, the distance mantle plumes need to penetrate into the stagnant lid to initiate decompression melting expressed as a fraction of the stagnant lid thickness $f=1-D_{\text {melt }} / D_{l}$, the same fraction assuming a locally heated mantle $f_{100}$, the fraction of extracted water from the mantle $f_{\mathrm{H}_{2} \mathrm{O}}$ and the ratio of calculated and measured potassium $K_{c a} / K_{m e}$ on the Martian surface are given.

\begin{tabular}{llllllllll}
\hline$T_{m}^{0}[\mathrm{~K}]$ & $D_{c r}^{0}[\mathrm{~km}]$ & $\Lambda$ & $D_{c r}^{4500}[\mathrm{~km}]$ & $D_{c r}^{500}[\%]$ & $\Delta T_{\min }[\mathrm{K}]$ & $f[\%]$ & $f_{100}[\%]$ & $f_{H_{2} O}[\%]$ & $K_{c a} / K_{m e}$ \\
\hline 1600 & 0 & 15 & 80 & 275 & 71 & 48 & 23 & 3.51 \\
1650 & 0 & & 33 & 86 & 293 & 72 & 51 & 42 & 1.94 \\
1700 & 0 & & 64 & 334 & 78 & 58 & 60 & 1.21 \\
1600 & 30 & 5 & 41 & 96 & 298 & 78 & 55 & 18 & 1.35 \\
1650 & 30 & 5 & 59 & 93 & 312 & 77 & 56 & 41 & 1.16 \\
\hline 1650 & 30 & 1 & 65 & 89 & 308 & 77 & 55 & 49 & 1.07 \\
1700 & 30 & 10 & 88 & 93 & 367 & 85 & 66 & 59 & 0.96 \\
1700 & 30 & 20 & 76 & 99 & 411 & 89 & 71 & 47 & 1.16 \\
\hline
\end{tabular}




\section{Research Highlights}

- We model the thermal and crustal evolution of Mars.

- Crustal recycling is common due to low mantle viscosities and an insulating crust.

- Observations suggest a primordial crust and low initial mantle temperatures.

- Dehydration stiffening of the mantle favors recent volcanism.

- Water extraction from the mantle is efficient and can exceed $40 \%$. 